\title{
Research Paper \\ Comparison of the Effectiveness of Cognitive Rehabilitation and Neurofeedback on Improving the Executive Functions in Children with Dyslexia
}

\author{
Nazanin Abbasi Fashami ${ }^{1}$, Bahman Akbari ${ }^{* 2}$, Abbas Ali Hosseinkhanzadeh ${ }^{3 \& 4}$ \\ 1. Ph.D. Student, Department oF Psychology, Rasht Branch, Islamic Azad University, Rasht, Iran \\ 2. Professor, Department of Psychology, Rasht Branch, Islamic Azad University, Rasht, Iran \\ 3. Invited Associate Professor, Department of Psychology, Rasht Branch, Islamic Azad University, Rasht, Iran \\ 4. Associate Professor, Department of Psychology, Faculty of Literature and Humanities, University of Guilan. Rast, Iran
}

Citation: Abbasi Fashami N, Akbari B, Hossein Khanzadeh AA. Comparison of the effectiveness of cognitive rehabilitation and neurofeedback on improving the executive functions in children with dyslexia. Quarterly Journal of Child Mental Health. 2020; 7(2): $294-311$.

\section{http://dx.doi.org/10.29252/jcmh.7.2.25}

\section{A R T I C L E I N F O}

\section{Keywords:}

Dyslexia,

executive functions, cognitive rehabilitation, neurofeedback

Received: 29 Mar 2020

Accepted: 20 Jun 2020

Available: 21 Sep 2020

\section{A B S T R A C T}

Background and Purpose: Dyslexia as one of the most prevalent learning disabilities may cause many cases of academic failure in primary school students. During the recent years, several research and clinical methods have been used to treat children with this disability. Present study was conducted to compare the effectiveness of cognitive rehabilitation and neurofeedback on improvement of executive functions in children with dyslexia.

Method: This research was a quasi-experimental study with pretest-posttest control group design with 2-month follow-up period. The study population included all the 8 to 12 -year old children with dyslexia who had referred to centers for learning disability in District 3 of Tehran in 2019, among which a sample of 36 students were selected by purposive sampling and then randomly assigned to one of the two experimental groups or the control group. One of the experimental groups received eleven 60-min sessions of rehabilitation with working memory training software and the second experimental group received thirty 45- min sessions of neurofeedback intervention, whereas the control group received no intervention. All the three groups were assessed at the stages of pretest, posttest, and two-month follow-up period. To collect the data, Reading and Dyslexia Test (Karami Nouri \& Moradi, 2008) and Behavior Rating Inventory of Executive Function (Gerard et al., 2000) were used. Repeated measures analysis of variance were used to analyze the data.

Results: Results of data analysis indicated that cognitive rehabilitation and neurofeedback were significantly effective in improving the components of executive functions at both pretest and posttest stages $(\mathrm{P}<.05)$. Also, comparison of means showed that there was no significant difference between the cognitive rehabilitation and neurofeedback in terms of their effects on the components of executive functions $(\mathrm{P}>.05)$. However, scores of the experimental groups were significantly different from those of the control group $(\mathrm{P}<0.05)$.

Conclusion: Based on the findings of this study, it can be concluded that cognitive rehabilitation by promoting the mental and intellectual abilities, and neurofeedback by providing positive and negative feedbacks and reinforce self-regulation can be effective in improving executive functions in children with dyslexia.

\footnotetext{
* Corresponding author: Bahman Akbari, Professor, Department of Psychology, Rasht Branch, Islamic Azad University, Rasht, Iran. E-mail addresses: Bakbari44@yahoo.com
} 


\section{مقايسه اثربخشى توانبخشى شناختى و نوروفيدبك بر بهبود كنشهاى اجرايى كود كان مبتلا به نارساخوانى}

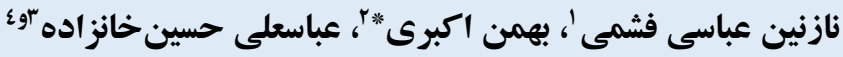

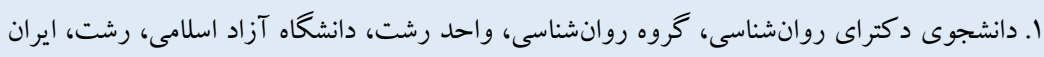

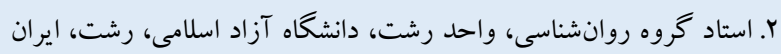

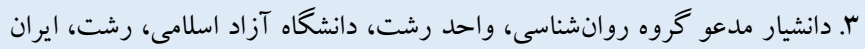

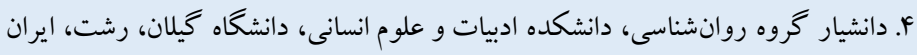

جكيده

مشخصات مقاله

زمينه و هدف: نارساخوانى به عنوان يكى از شايع ترين اختلالات ياد گيرى، علت بسيارى از موارد افت تحصيلى دانش آموزان دبستانى است.

كليدوازهها:

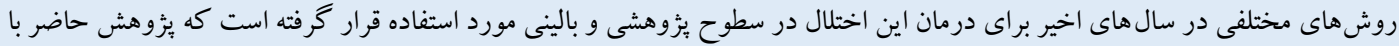

نارساخوانى،

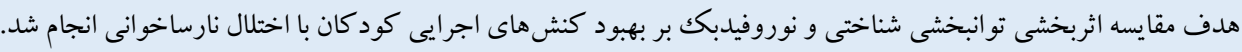

كنشهاى اجرايى،

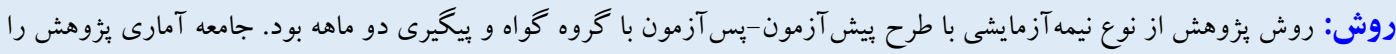

تو انبخشى شناختى،



نوروفيدبك

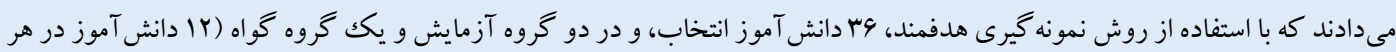

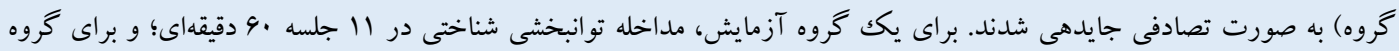

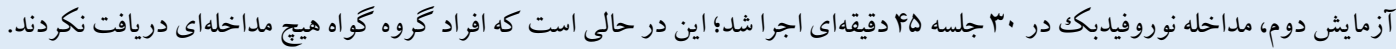

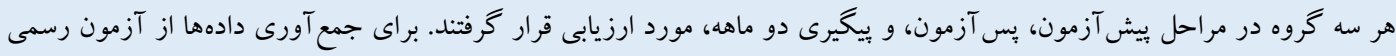

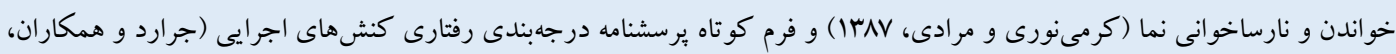

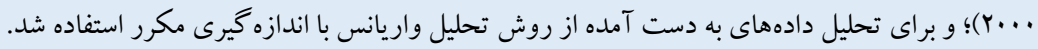

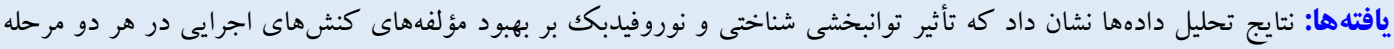

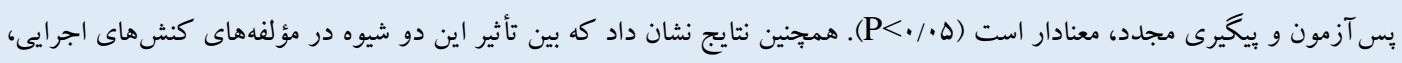

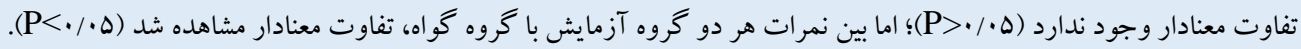

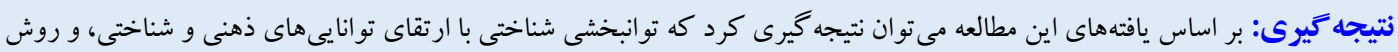


مطالعات طولى نشان مىدهند كه كنشهاى اجرايى با موفقيت تحصيلى،

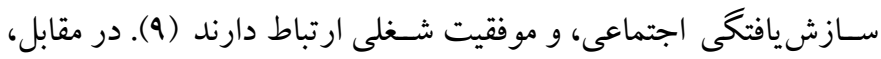

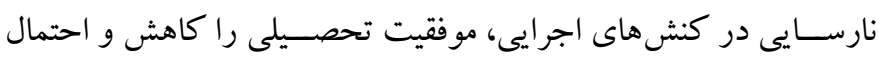

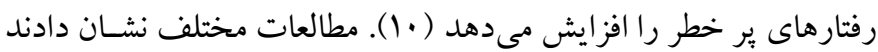

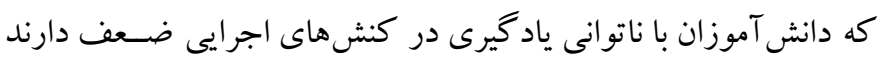

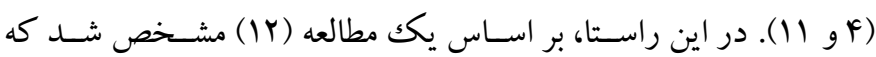

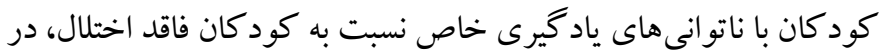

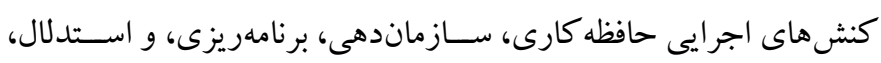

$$
\text { نمر ات كمترى كسب كردند. }
$$

امروزه متخصـصـان معتقدند كه بهترين شـيوه مقابله با ناتوانىهاى

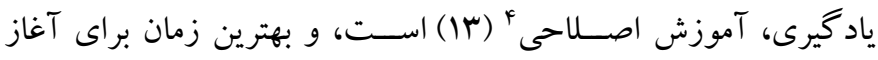

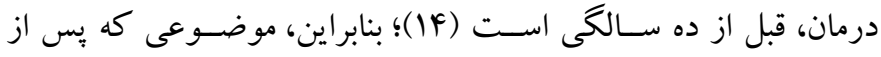

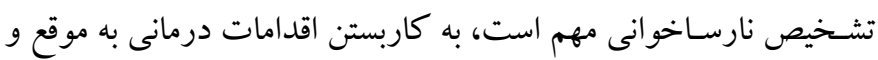

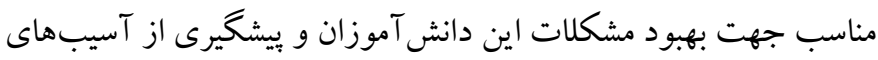

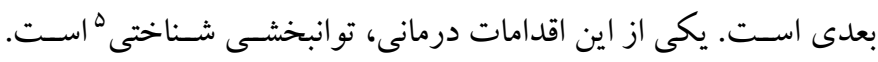

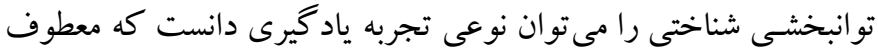

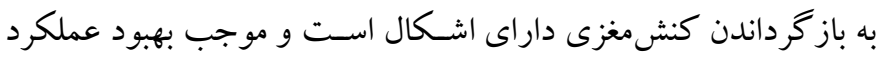

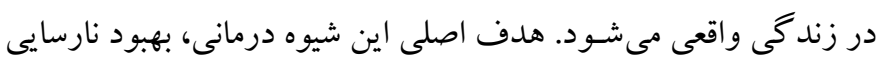

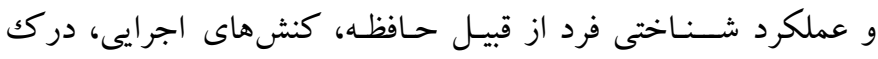
اجتماعى، تمركز، و توجه است. درمان به روش تو انبخشى از اين نظر كه له

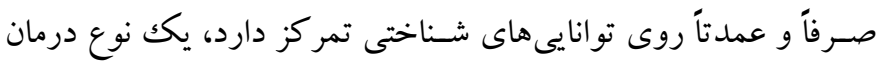

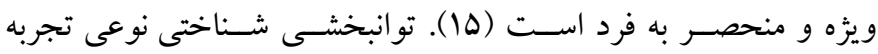

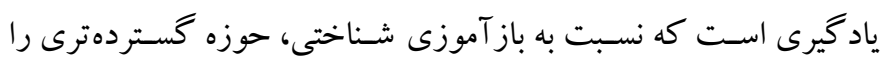

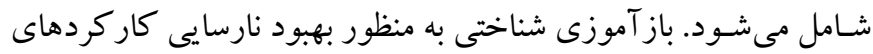

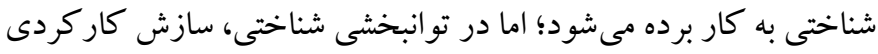

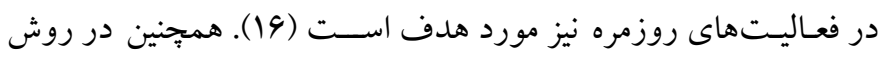

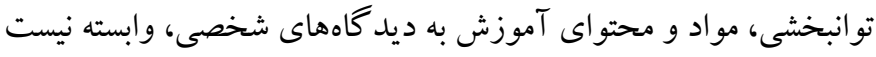
(IV)

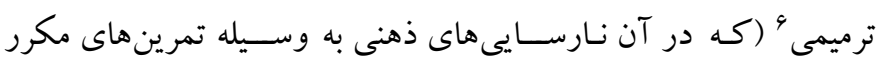

4. Remedial instruction

5. Cognitive rehabilitation

6. Restorative مقلdo

خواندن يكى از عمدهترين روشهاى كسـب دانش محسـوب مى شـود و

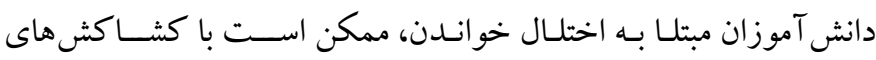

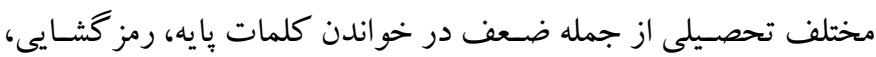
املاء، تسـلط در خواندن، و دركك مطلب مواجه شــوند كه اين مســئله مى تو اند بر عملكرد تحصـيلى و روانى اجتماعى آنها، تأثير منفى بخذارد

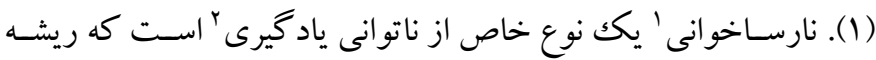

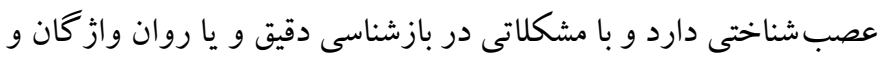

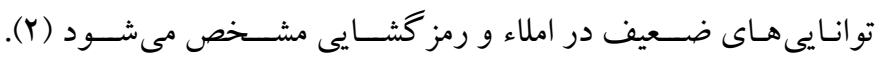

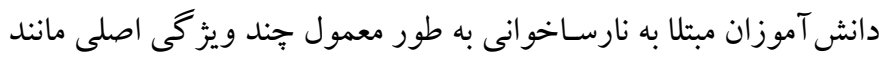

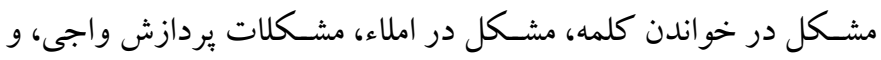

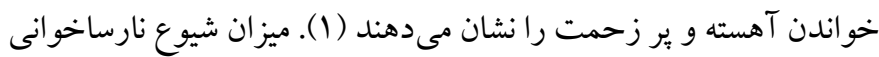

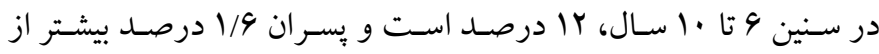
دختران به اين اختلال مبتلا هسـتند. ميزان شـيوع اين اختلال در ايران، ه/هـ

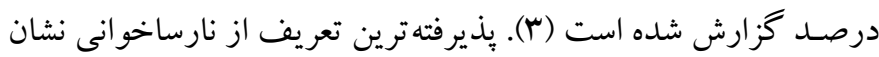

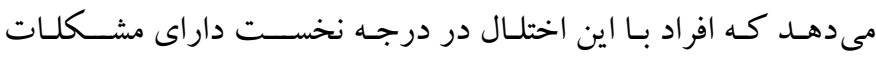

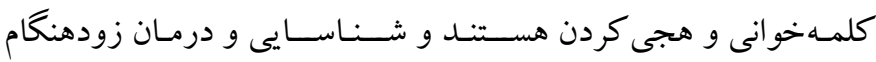

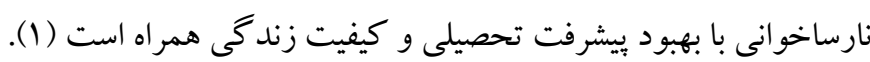

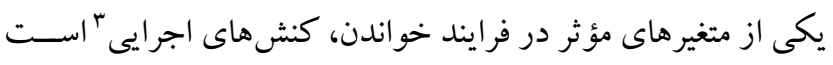

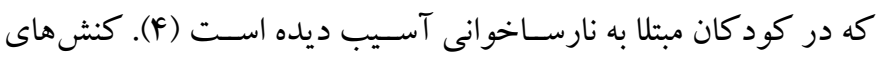

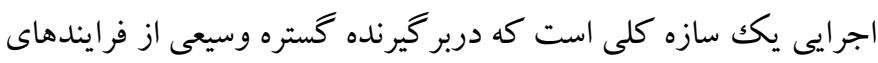

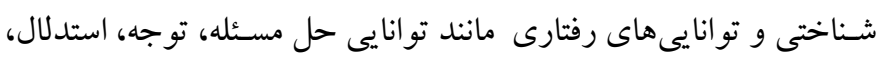

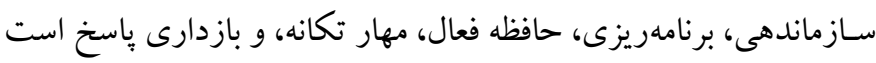

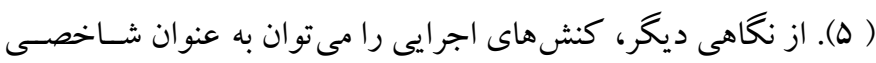

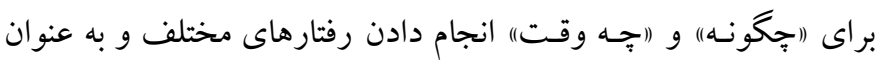

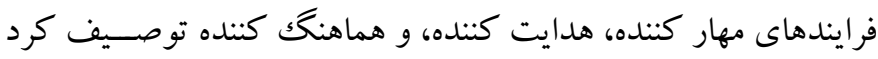

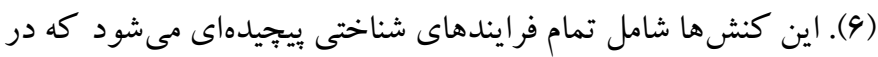

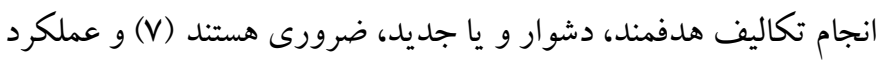

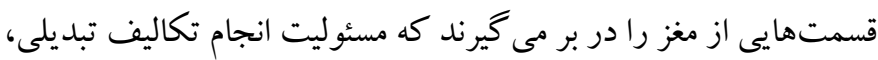
تكـاليف جنــدوظيفـهاى، و دو تكليف موازى را بر عهـده دارنــ (A).

1. Dyslexia

2. Learning disabilities

3. Executive functions 
موفق تر عمل كنند ( آ). در همين راستا، يزوهش هاى متعدد نشاندهنده

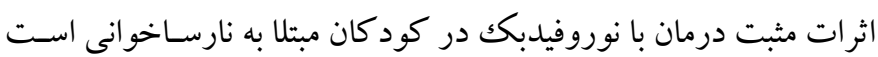

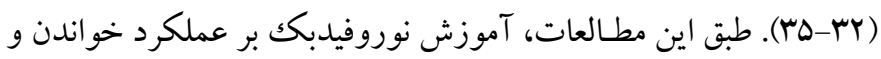

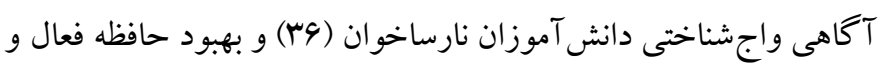

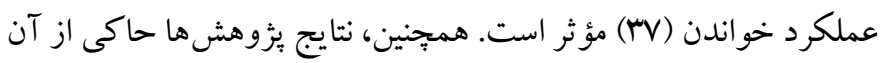

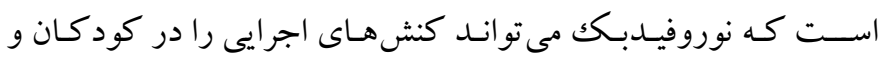

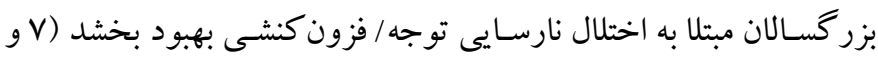

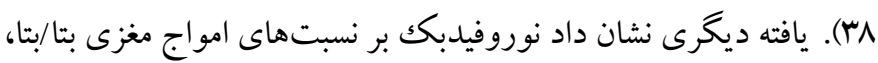

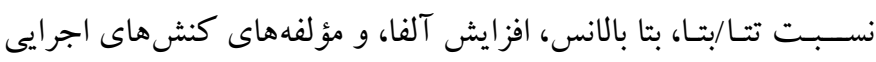

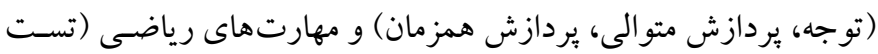

$$
\text { رياضى)، مؤثر بوده است (19). }
$$

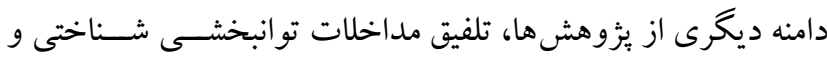

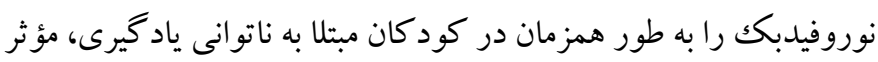

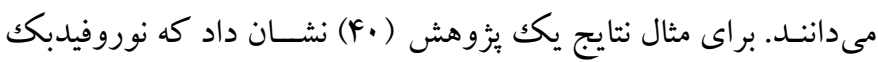

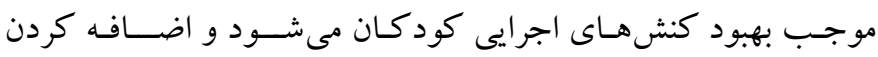

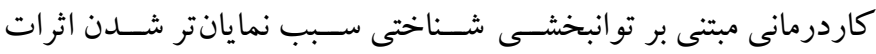

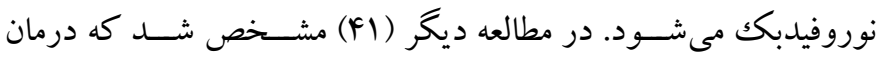

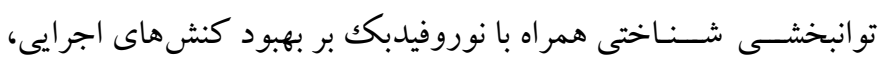
حافظه، و توجه مؤثر است. همـانطور كه بيان شـــ، مطالعات مختلف اثرات مثبت تو انبخشـى ونى

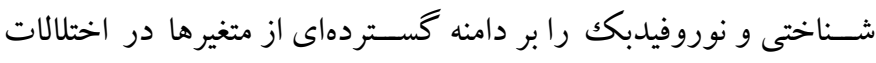

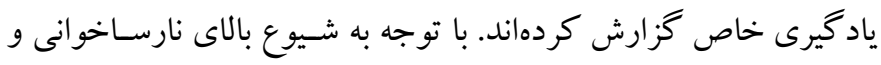

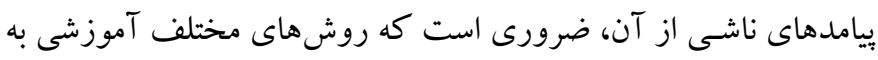

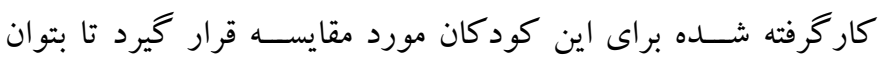
مناسـبترين و كار آمدترين روش را با توجه به نظام آموزشسى كشــور

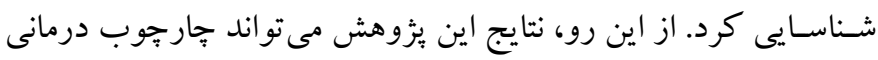

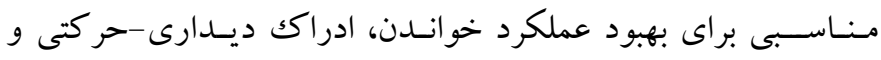

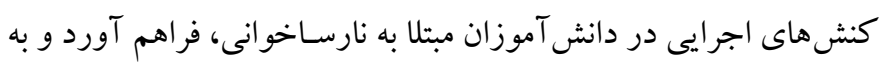

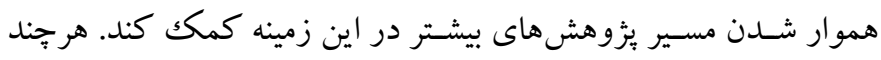

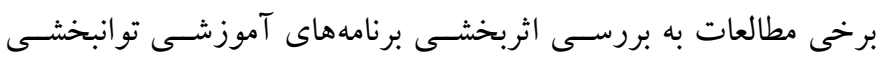

3. Self-regulation
كونـاگون ترميم مىشـود) و روش جبرانى ' (كسه در آن راهبردهـاها و

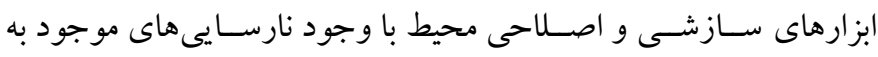

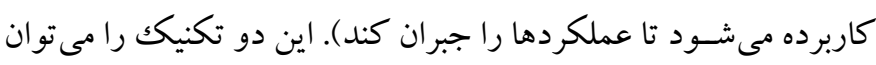

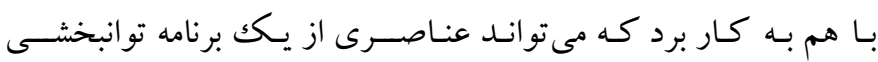

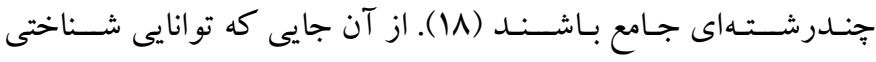
دانش آموزان مبتلا به نارسـاخوانى آسيب ديده است، تو انبخشى شناختى

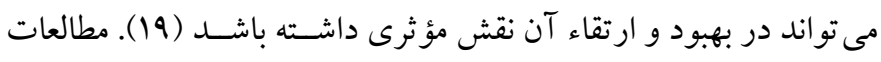

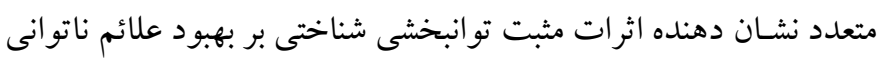

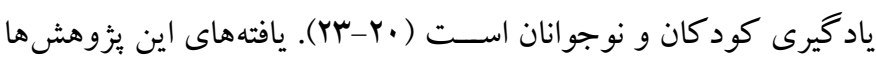

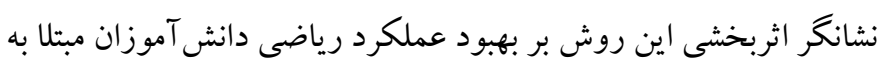

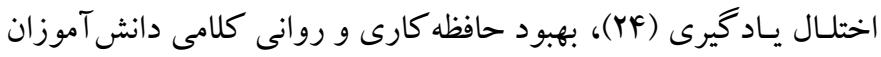

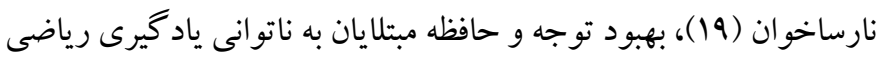

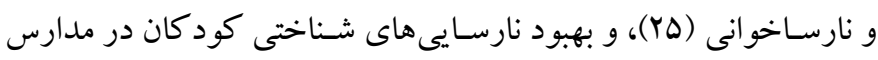
ابتدايى و متوسطه (Y9) است.

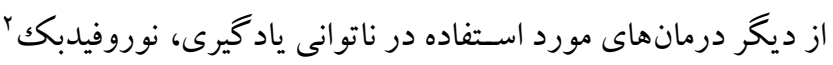
اسـت (YV) كه تلاش مى كند از طريق ثبت بِاســخ هاى الكتريكى و وارائه

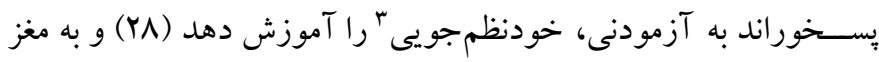

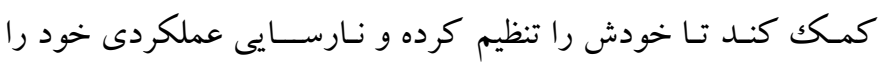
برطرف سازد (V). اساس درمان نوروفيدبكك مبتنى بر اين نظريه است كه

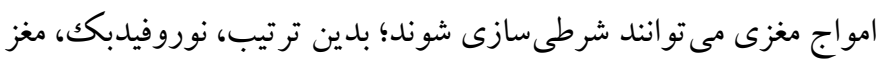

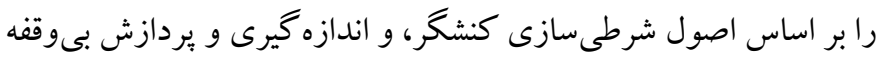

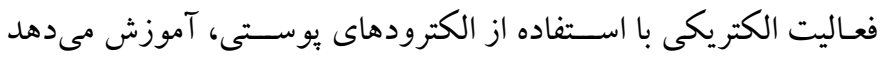

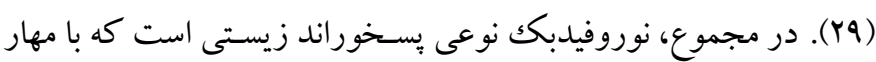

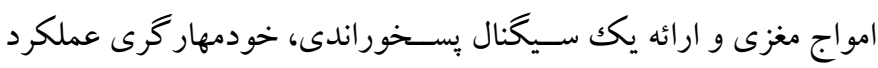
مغز را به افراد آموزش مى مدهد (•r). شـواهد حاكى از آن اسـت كه افراد با اختلال نارسـاخوانى در تحول

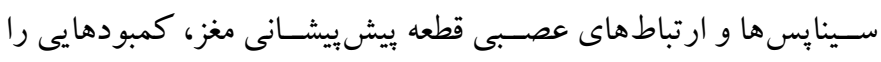

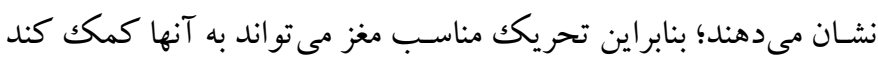

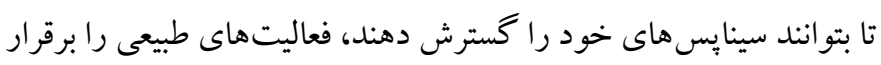

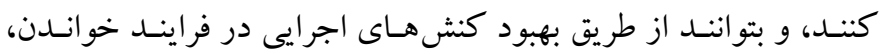

1. Compensatory

2. Neurofeedback 
ادامه درمان و مشار كت در يُزوهش، و عدم مصرف داروهاى روانيز شكى

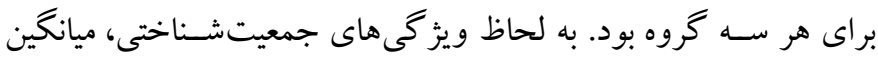

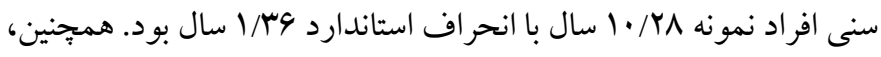

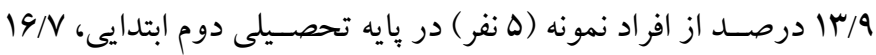
درصد (4 نفر ) در بايه تحصيلى سوم ابتدايى، 19/4 درصد (Vنقر ) در بايه

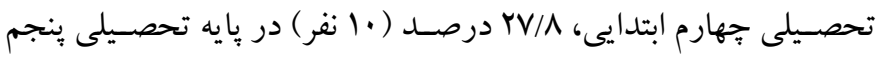

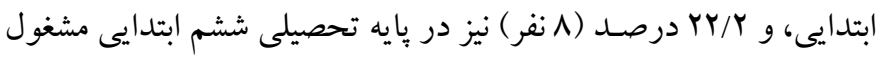
به تحصيل بودند.

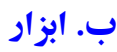
ا ـ آزمون رسـمى خواندن و نارسـاخوانى نما: در يزوهش حاضـر از اين

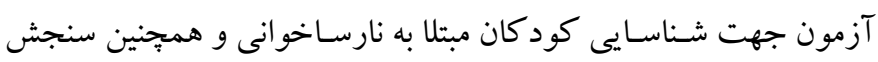

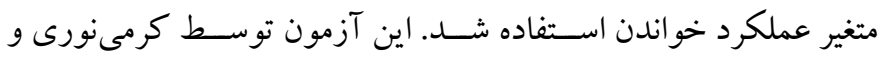

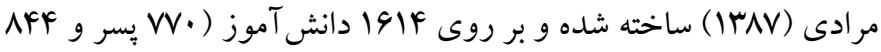
دختر ) در بنج بايه تحصيلى شهر تهران، سنندج، و تبريز هنجاريابى شد.

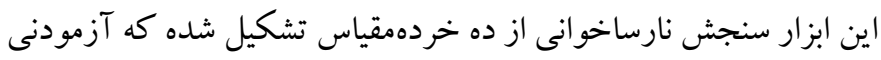

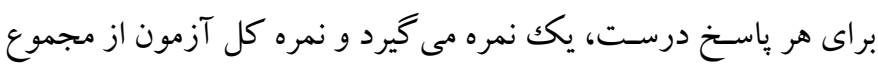

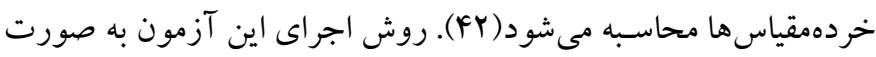

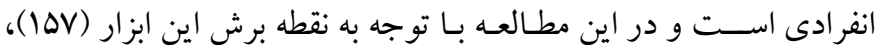

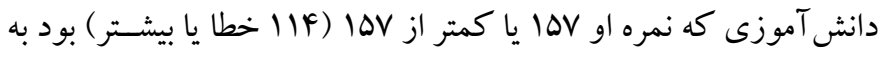

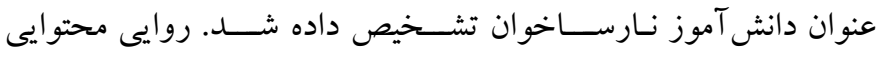

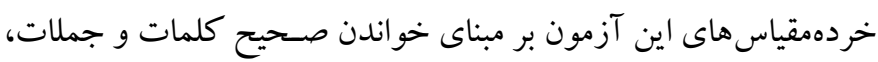

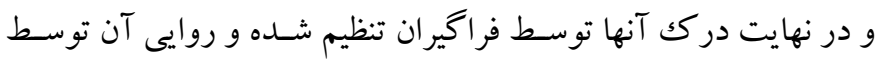

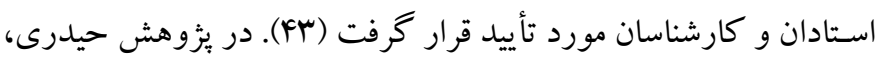

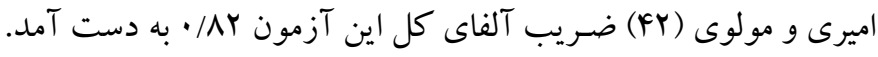

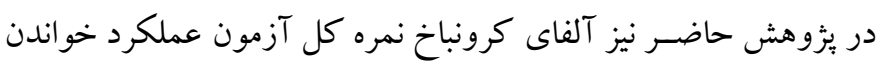

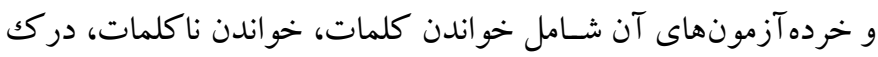
متن، حذف آواها، قافيهها، ناكلمات، دركك كلمات، نشانه حروف، نشانه كلمـات و نـاميـدن تصساوير به ترتيب ••// •،

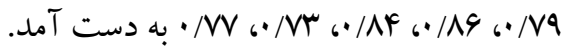

شـناختى و نوروفيدبكك بر مشـكلات دانش آموزان مبتلا به نارسـاخوانى يرداختهاند؛ با اين حال، درباره مقايسـهـ اين روشهاى مداخله، خلأهاى

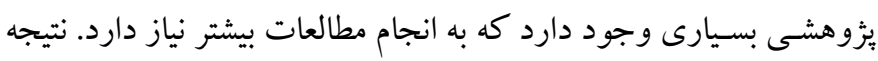

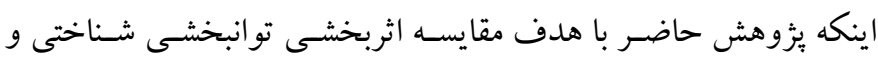

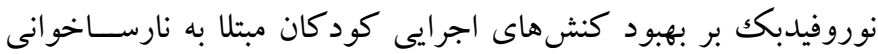

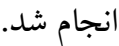

روش الف) طرح بزوهش و شـر كت كنند كان: يزولهش حاضر نيمه تجربى با

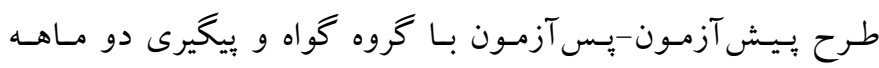

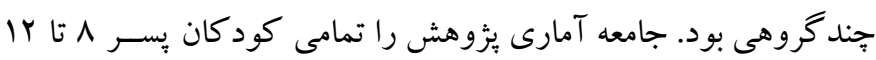

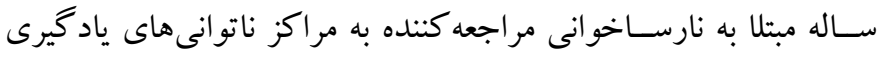

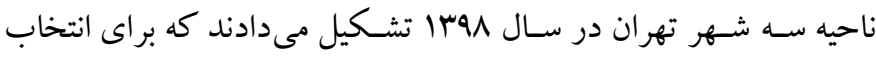

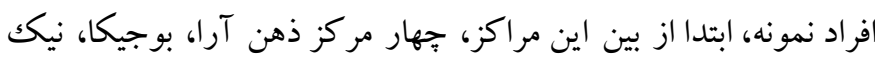

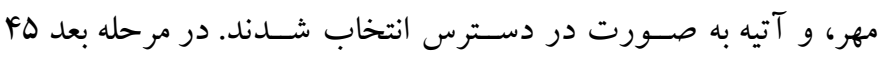
دانش آموز بر حسـب شـــايط ورود و خروج به صـورت در دسـترس،

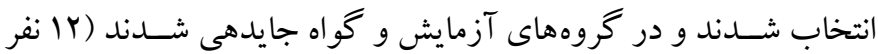

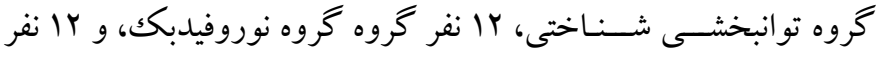

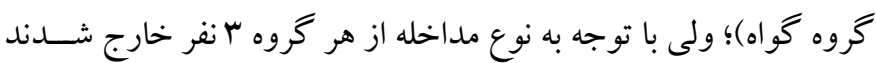
(به علت غيبت بيش از دو جلسه و عدم تمايل به ادامه شركت در جلسات

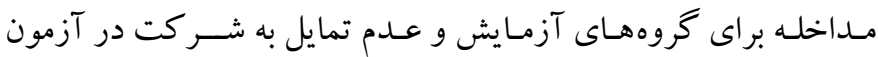

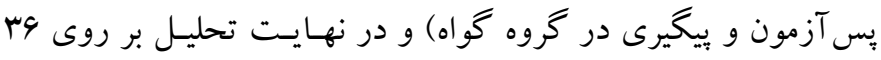

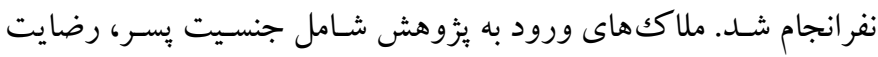

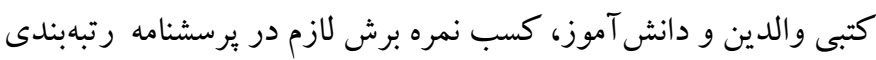

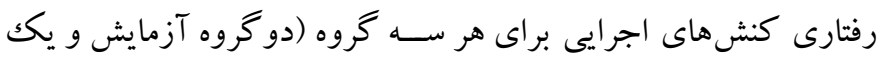

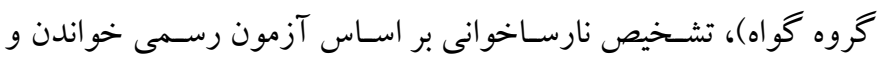

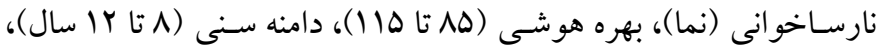
عدم ابتلا به اختلال عصبى تحولى يا اختلالات روانشناختى همزمان ديخر بهر

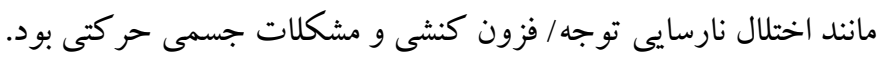

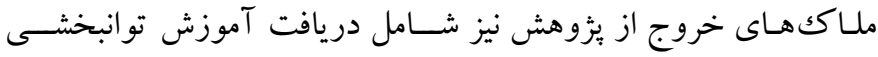

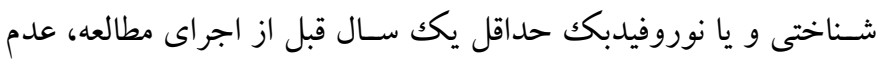

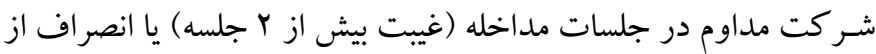


ا. روش مـداخله نوروفيـدبـك: هـــف اين برنـامه، يادگيرى تدريجى

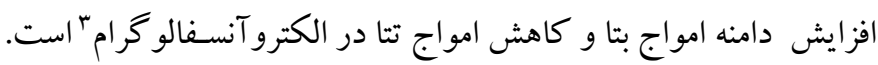

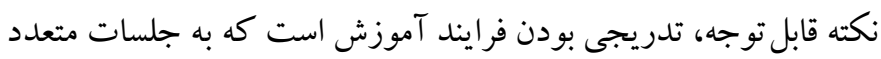

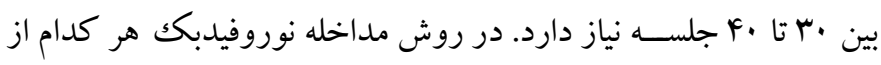

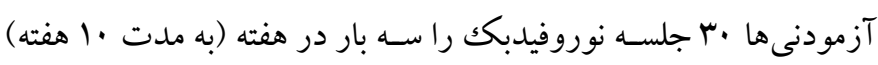

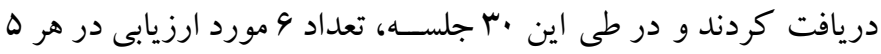

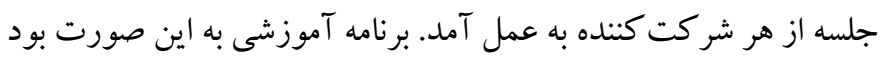

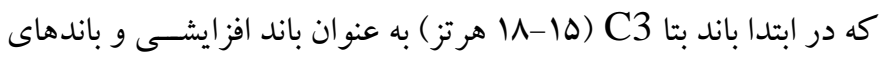

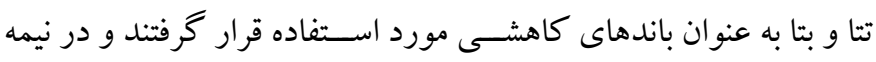

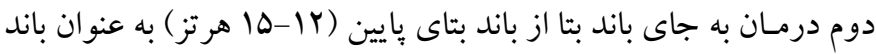

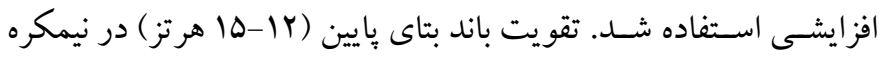

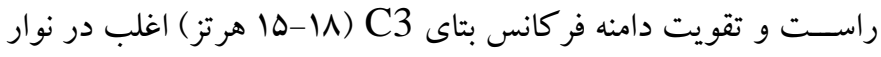

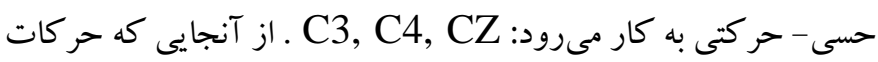

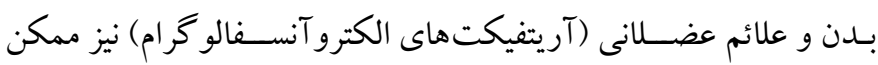
اسـت موجب ايجاد امواج مصـنوعى مغز شـوند، براى حصول اطمينان از

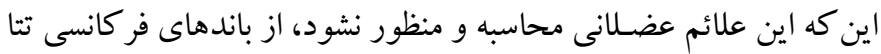

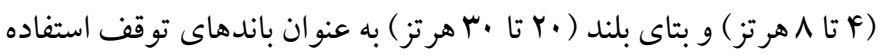

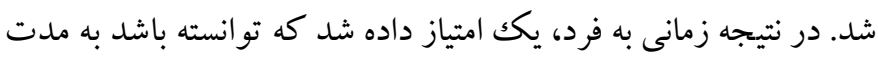

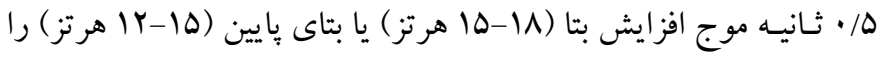

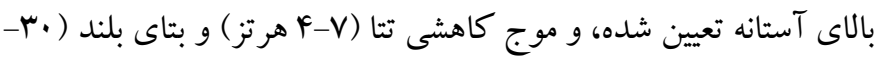

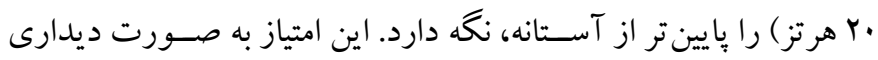
(در صـفحه بازى انتخاب شــه)، نمره (ثبت شــده در صـفحه رايانه)، و

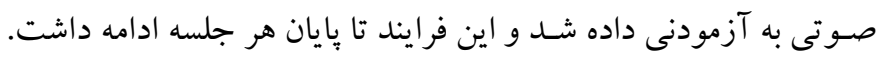
در مورد اتصـال الكترودها بر روى سر مطابق با سيستم بين المللى ·r-1. عمل شـد؛ به اين ترتيب كه در نيمه اول درمان، الكترود اصسلى در محل

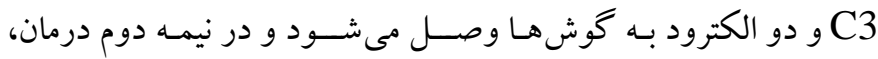

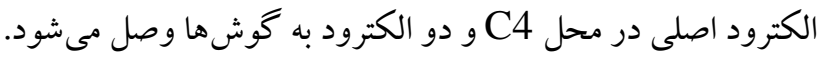
r. روش مداخله توانبخشى شناختى: توانبخشى شناختى به وسيله نرمافزار

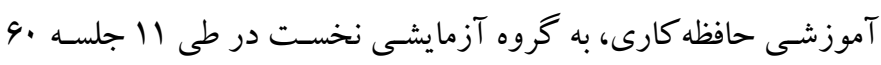

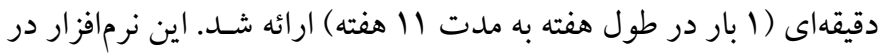

3. Electroencephalogram r. برسـشــنامه رتبهنبلدى رفتارى كنش هاى اجرايى (فرم كوتاه) ': اين

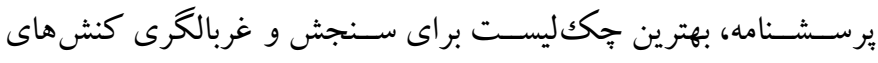

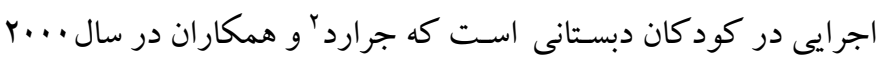

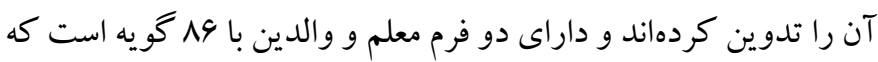

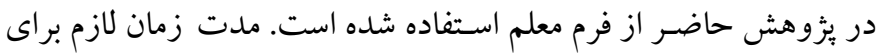

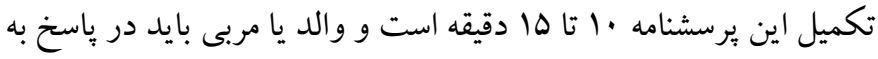

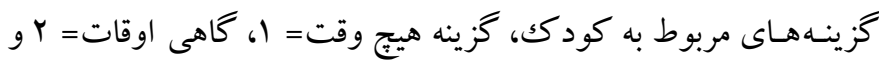

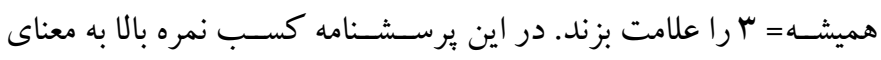

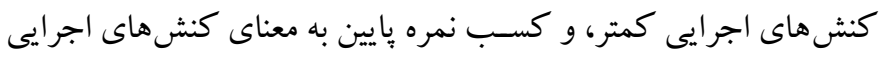
بيشتر است. اين يرسشنامه به منظور تفسير رفتارى كنش اجرايى كود كان

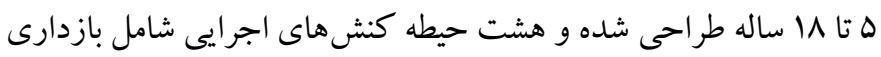

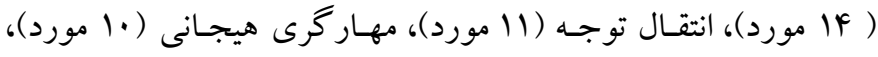

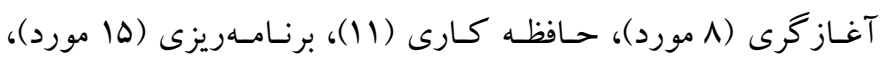

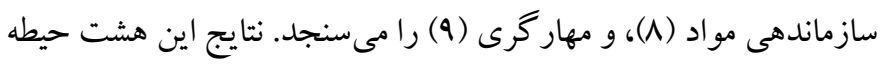
در دو شــاخص هميوش خلـاصـهـ مى شـــونـد: مهارتهاى تنظيم رفتار

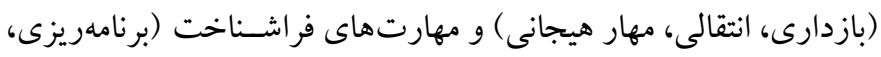

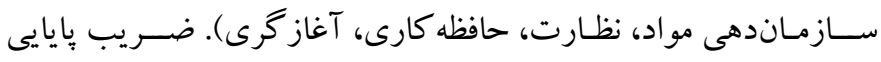

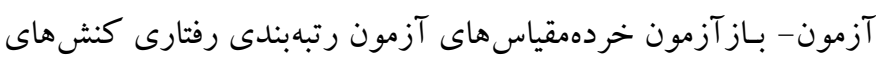

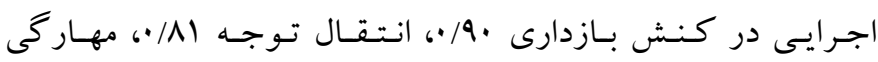

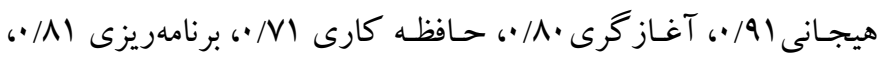

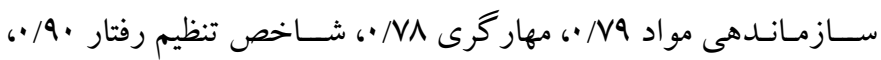

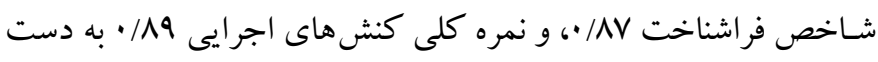

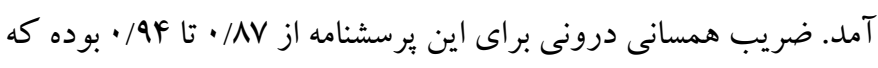

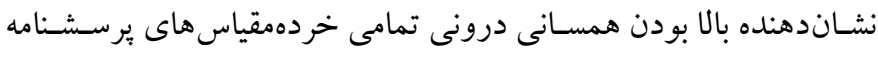


هميوش مهارت هـاى تنظيم رفتـار و مهارتهاى فراشـناخت و همرجنين

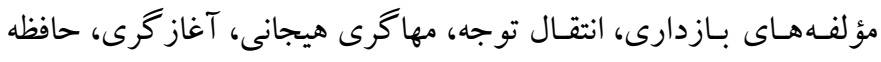

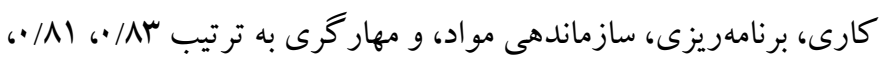

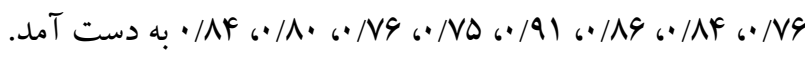

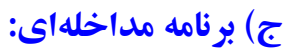

1. Behavior rating inventory of executive function (BRIEF) 2 .Gerard 
مى كند. سـح دشـوارى تكاليف به گونهاى طراحى شـد كه با بيشـرفت

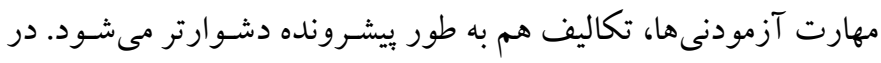

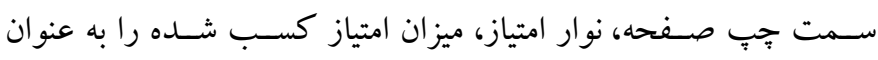
يسـخوراندى از تمرين براى كاربر فراهم مى كند و براى هر كوشـش

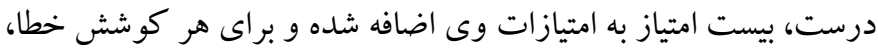

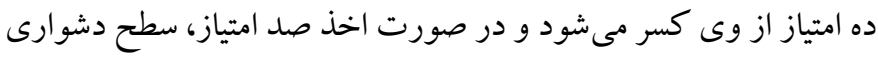

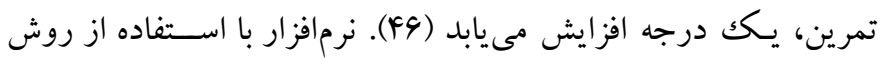

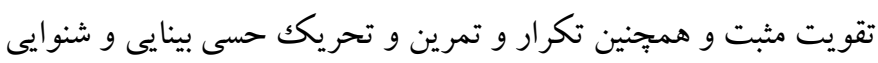

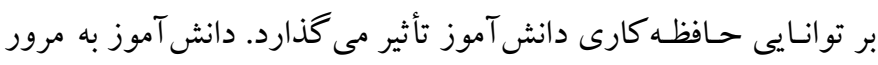

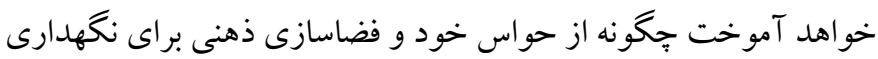
بيشـتر اعداد و حروف در ذهنش اسـتفاده كند. خلاصـه جلسـات برنامه آموزش توانبخشى در جدول اكزارش شده است.

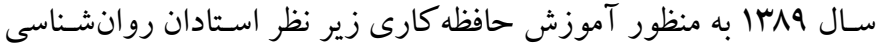

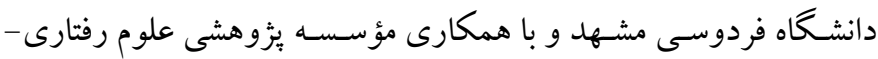

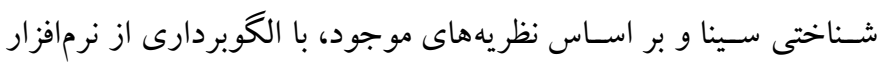

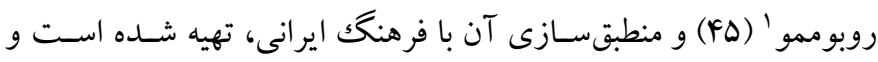

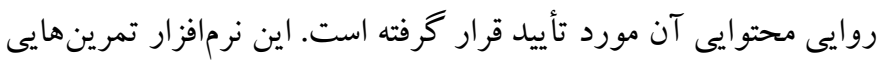

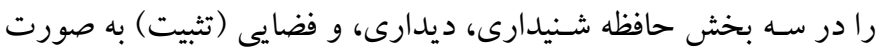
جداكانه با اسـتفاده از اعداد، حروف، و اشـكال به كاربر ارائه مىدهد. درجه دشـوارى در هر تمرين از يكك تا نه طبقهبندى شـده اسـت و كاربر

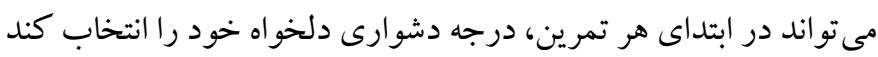

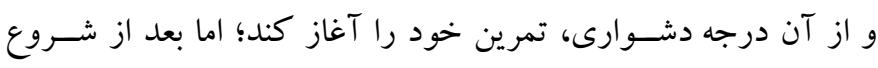

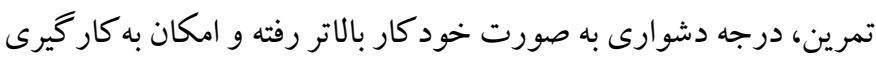

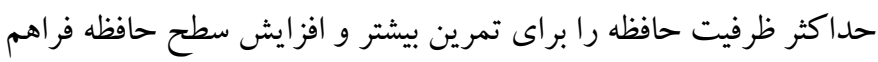

جدول 1: خلاصه جلسات برنامه آموزش توانبخشى شناختى

اهداف و محتواى جلسات

\section{جلسات}

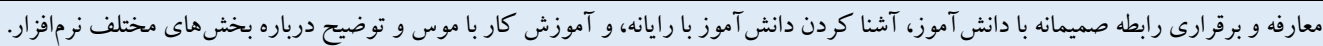

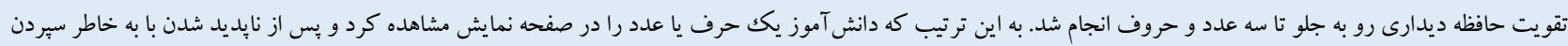

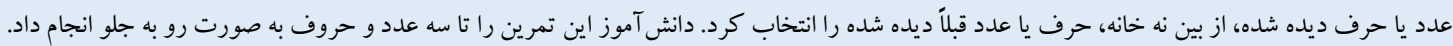

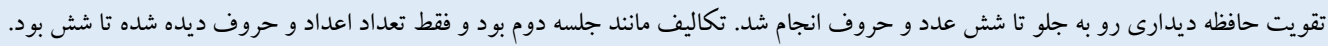

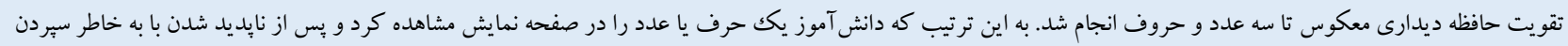

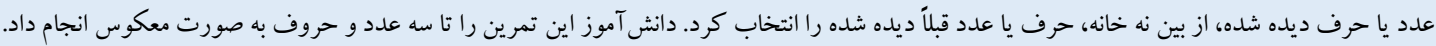

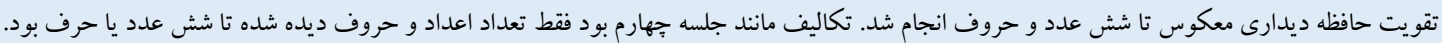

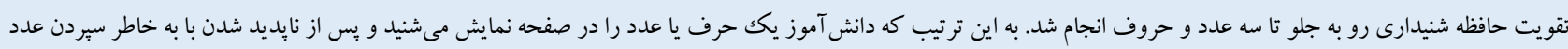

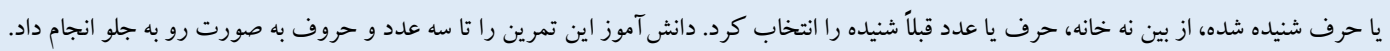

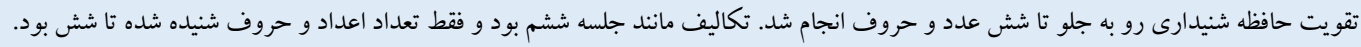

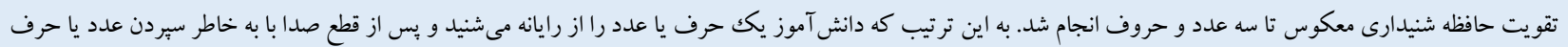

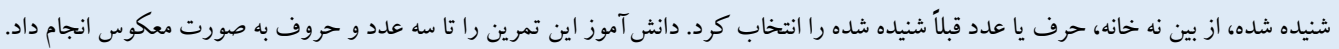

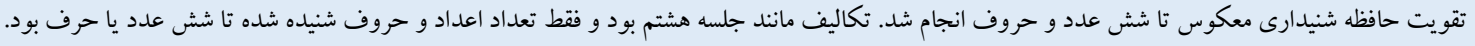

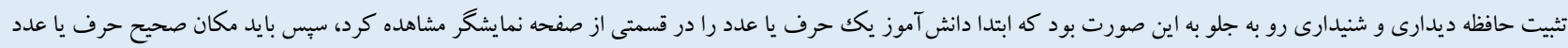

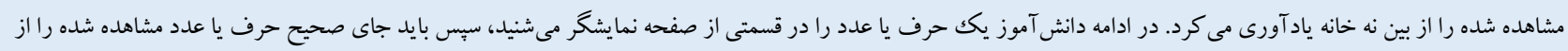

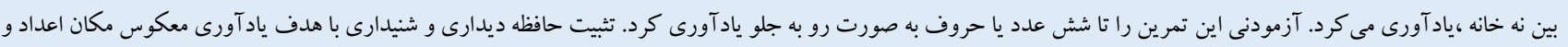
حروف ديده و شنيده شده، انجام شد.

تثبيت حافظه ديدارى و شنيدارى معكوس تكاليف، مشابه جلسه دهم بود؛ با اين تفاوت كه دانش آموز مىبايست مكان اعداد و حروف ديده اندام و شنيده شده را به صورت معكوس يادآورى مى كرد.

\section{Robo Memo}


كواه نيز در فهرست انتظار بود و هيج گونه درمانى را دريافت نكرد. سبس

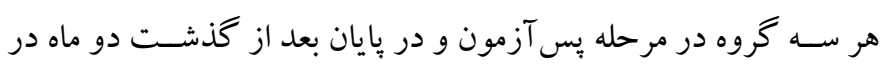

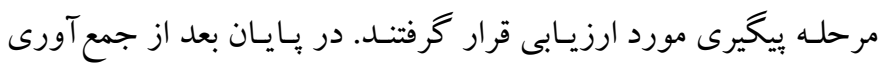

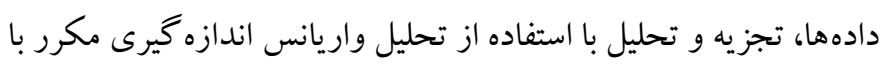

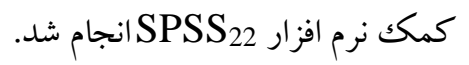

\section{يافته ها}

اطلاعات توصيفى شامل ميانخين و انحراف معيار متغير كنشهاى اجرايى

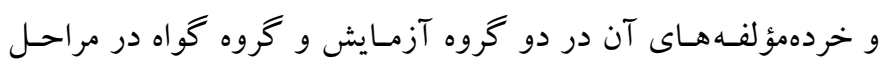

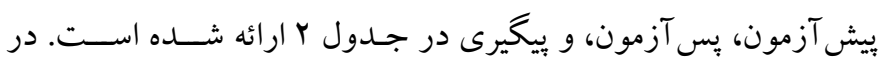

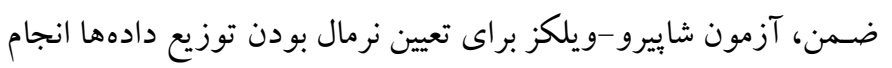

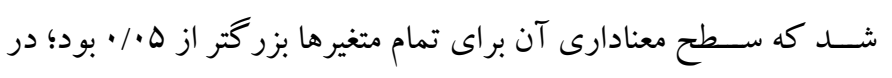

$$
\text { نتيجه توزيع تمامى متغيرها نرمال است (ه •/p>). }
$$

د) روش اجر ا: جهـت اجراى يُزوهش، بـ از دريـافت معرفىنـامـه از

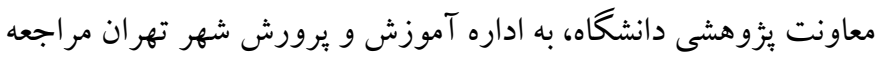

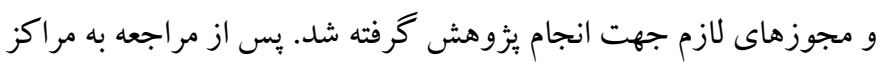

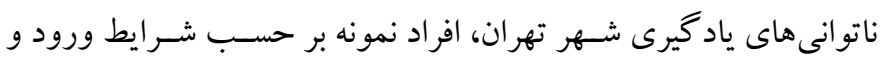

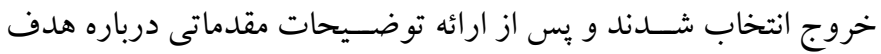

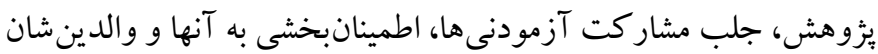

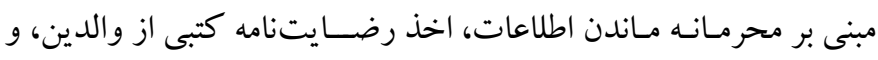

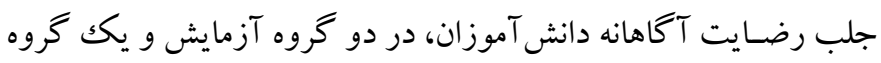

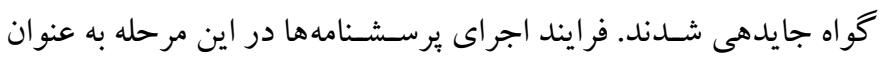

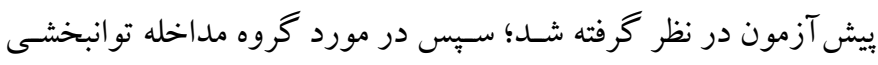

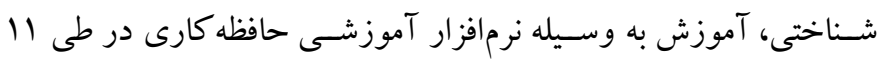

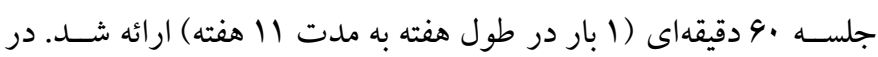

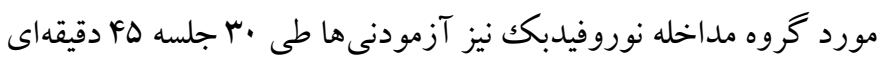

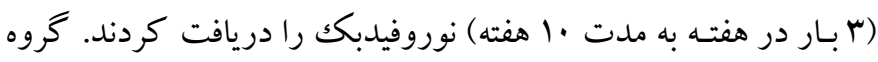

جدول ץ: شاخصهاى مر كزى و ير اكندكى متغيرهاى ثئوهش در سه كروه

\begin{tabular}{|c|c|c|c|c|c|c|c|c|}
\hline \multicolumn{2}{|c|}{ يُگيرى } & \multicolumn{2}{|c|}{ يس آزمون } & \multicolumn{2}{|c|}{ بيش آزمون } & \multirow{2}{*}{ كروه } & \multirow{2}{*}{ مقياسها } & \multirow{2}{*}{ متغير } \\
\hline SD & $\mathbf{M}$ & SD & $\mathbf{M}$ & SD & $\mathbf{M}$ & & & \\
\hline r/Fr & $r \cdot / \Delta \Lambda$ & $r / \Delta r$ & rV/Ar & $F / q V$ & Fr & توانبخشى شناختى & \multirow{3}{*}{ مهارتهاى تنظيم رفتار } & \multirow{20}{*}{ كنشهاى اجرايى } \\
\hline r/Q1 & rr & $r / M$ & $r \cdot / 19$ & $r / \cdot V$ & FF/VD & نوروفيدبكك & & \\
\hline$r / 9 \Lambda$ & $F \mid / \Delta \Lambda$ & $F / 19$ & $r \cdot / \Lambda r$ & $\Delta / 1$. & $F Y / F I$ & كواه & & \\
\hline F/VG & Fr & r/va & $F \cdot / \Delta \Lambda$ & $\Delta / 9 Y$ & $\Delta \Delta / Y \Delta$ & توانبخشى شناختى & \multirow{3}{*}{ مهارتهاى فراشناختى } & \\
\hline $9 / N 9$ & $F F / 19$ & $9 / 19$ & Fr/94 & $N / \Delta r$ & $\Delta F / \cdot \Lambda$ & نوروفيدبك & & \\
\hline$\Delta / \Delta 1$ & $\Delta \Delta / q 1$ & $9 / .1$ & $\Delta 9 / \Gamma \mu$ & $9 / Y \Lambda$ & $\Delta V / \Delta$. & كواه & & \\
\hline $1 / 41$ & 1. & س & $\Lambda / \Delta$ & $r / F F$ & if & توانبخشى شناختى & \multirow{3}{*}{ 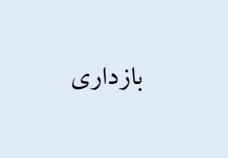 } & \\
\hline $1 / 9 \mathrm{~V}$ & $9 / \Delta \wedge$ & $1 / \lambda$. & $N / \Delta r$ & $1 / r 9$ & $\mid F / \Delta r$ & نوروفيدبك & & \\
\hline $1 / \wedge \Delta$ & 10 & $1 / 41$ & IF/Ar & $1 / \wedge 9$ & $10 / 19$ & كواه & & \\
\hline$r / I V$ & $1 . / v \Delta$ & r & 1. & $r / r V$ & $I F / N \Delta$ & توانبخشى شناختى & \multirow{3}{*}{ انتقال توجه } & \\
\hline 1/A9 & $I Y / Y \Delta$ & l/Ar & $11 / \Delta$ & $1 / 9 Y$ & $\mid 9 / 41$ & نوروفيدبك & & \\
\hline$r / \Delta$. & $\mid F / \Delta \Lambda$ & $r / 99$ & $1 F / 19$ & $r / 19$ & 10 & كواه & & \\
\hline$r / \cdot \wedge$ & $9 / \wedge r$ & $r / 1$. & $9 / \Gamma$ & r/ar & $\mid r / T \Delta$ & توانبخشى شناختى & \multirow{3}{*}{ مهار گرى هيجانى } & \\
\hline$r / \mu r$ & 1.119 & $r / Y \Lambda$ & Q/A & $r \cdot / r$. & $1 r / 0$ & نوروفيدبك & & \\
\hline $1 / v$ & ir & I/IV & II/Ar & $r / l r$ & $9 / \pi r$ & كواه & & \\
\hline $1 / r V$ & $\wedge$ & 1/14 & V/VD & $1 / 94$ & $1 \cdot / \pi r$ & توانبخشى شناختى & \multirow{3}{*}{ آغاز گرى } & \\
\hline $1 / 9 V$ & $9 / \cdot \wedge$ & $1 / V^{F}$ & N/Ar & $r / \cdot \Delta$ & 1.199 & نوروفيدبك & & \\
\hline $1 / \Delta$ & $1 \cdot / 91$ & $1 / \Delta \wedge$ & l./Ar & $1 / \wedge \Delta$ & $11 / 19$ & كواه & & \\
\hline $1 / \cdot r$ & $1 / 19$ & •/Ar & V/Ar & $1 / r V$ & 1.194 & توانبخشى شناختى & \multirow{2}{*}{ حافظه كارى } & \\
\hline r & $\Lambda / Y \Delta$ & $1 / 9 \mathrm{~V}$ & $\Lambda / \cdot \Lambda$ & $r / r Y$ & $1 \cdot / r \Delta$ & نوروفيدبك & & \\
\hline
\end{tabular}




\begin{tabular}{|c|c|c|c|c|c|c|c|}
\hline INY & $1 \cdot \% \cdot 1$ & $1 / 91$ & $1 . / \% \Delta$ & I/Ar & $1 \cdot / 0$ & كواه & \\
\hline$r / \Delta V$ & $1 . / 41$ & $r / r q$ & $1 \cdot 1 \cdot 1$ & $r / \wedge q$ & $\mid r / v \Delta$ & توانبخشى شناختى & \\
\hline r/gF & $1 \cdot / 0$ & $r / v$ & $1 . / \% \Delta$ & $r / 9 \Lambda$ & ir & نوروفيدبك & برنامهريزى \\
\hline$r / Y r$ & $\mid F / Y \Delta$ & $r / r$. & $\mid F / \pi r$ & $r / r q$ & $\mid F / \Delta \Lambda$ & كواه & \\
\hline I/.r & $\mathrm{V} / 19$ & .194 & $9 / 91$ & $1 / 10$ & $9 / 94$ & توانبخشى شناختى & \\
\hline $1 / 1 r$ & $\wedge$ & $\cdot / 19$ & $\mathrm{~V} / \mathrm{V} \Delta$ & $1 / F F$ & $9 / 91$ & نوروفيدبك & سازماندهى مواد \\
\hline I/FY & $q / v \Delta$ & $1 / \Delta \Lambda$ & Q/Ar & $1 / 9 \mathrm{~V}$ & $9 / 91$ & كواه & \\
\hline $1 / \wedge 1$ & $\Lambda / Y \Delta$ & $1 / F V$ & $\wedge$ & $1 / 94$ & I./A & توانبخشى شناختى & \\
\hline $1 / 91$ & $\Lambda / r r$ & $1 / \pi \Delta$ & $\mathrm{V} / \mathrm{VQ}$ & $r / F I$ & $1 \cdot / r \Delta$ & نوروفيدبك & مهارگرى \\
\hline $1 / 9 V$ & $1 . / 91$ & $1 / 94$ & $11 / \cdot 1$ & I/AV & س/r & كواه & \\
\hline
\end{tabular}

Tاره F تحليل واريانس دقيق نباشد. براى رفع اين مشكل و افزايش دقت

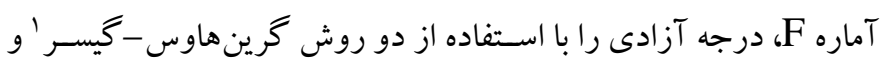
هاين -فلت ' تصسحيح مى كنند. براى اينكه از كدام روش تصحيح استفاده

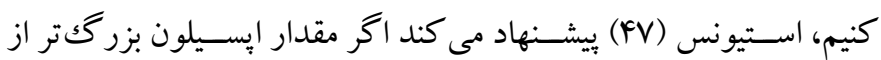

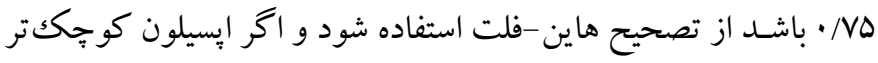
از Dه/ • و يا هيج كونه اطلاعاتى در مورد كرويت وجود نداشته باشد از تصحيح گرينهاوس - گيسر استفاده شود. بنابراين با در نظر گرفتن مقادير إيسيلون در جدول س نتايج آزمون تحليل واريانس با تكرار سنجش براى كروهها ارائه شده است.
براى بررسـى تأثير مداخله توانبخشـى شــناختى و نوروفيدبك بر مؤلفهاى كنشهاى اجرايى، از تحليل واريانس با تكرار سنجش استفاده شــــ. در اين بثزوهش يكك عامل درون آزمودنى وجود داشــت كه زمان اندازه گيرى متغيرهاى يزٔوهش در سـه مرحله بيش آزمون، يس آزمون، و بيخيرى بود و يكك عامل بين آزمودنى وجود داشت كه عضويت گروهى بود؛ بنابراين طرح مورد بررسى طرح درون-بين آزمودنى اسـت. قبل از

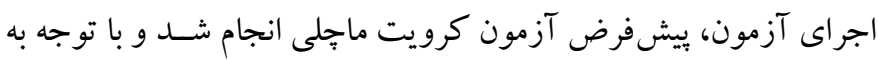
اينكه سـطح معنادارى براى تمامى مؤلفهها يايين تر از هـ • • بود، در نتيجه اين بيشفرض هم تأييد نشد. تخطى از بيشفرض كرويت باعث مى شود

جدول بّ: نتايج تحليل واريانس اندازهكيرى مكرر براى بررسى تفاوت تروهها در خردهؤلفههاى كنشهاى اجرايى

\begin{tabular}{|c|c|c|c|c|c|c|}
\hline اندازه اثر & $\mathbf{p}$ & $\mathbf{F}$ & خطا MS & MS آزمايشى & منابع تغييرات & مؤلفه \\
\hline$\cdot / 4 A$ & $\cdot / \cdot \cdot 1$ & $10 / T r$ & $F 1 / 9 V$ & 9rq/9r & كرووها & \\
\hline /ar & $\cdot / \cdot 1$ & FqA/V. & $r / 99$ & MAFT/AY & مر احل & مهارت هاى تنظيم رفتار \\
\hline$\cdot / \wedge \Delta$ & $\cdot / \cdot 1$ & QT/R & $r / 99$ & $M F \Delta / T V$ & تعامل مر احل با خروه & \\
\hline$\cdot / 41$ & $\cdot / \cdot \cdot 1$ & $11 / 94$ & $1.9 / \% 0$ & $1 \% r q / 99$ & كروهoا & \\
\hline.$/ 94$ & $\cdot / \cdot 1$ & $\mathrm{FrI} / \mathrm{A}$. & $r / .9$ & $1 \pi r r / \cdot 9$ & مر احل & مهارتهاى فراشناختى \\
\hline ·/Ar & $\cdot / \cdot \cdot 1$ & $\Lambda Y / V I$ & $r / .9$ & $r \Delta T / F \Delta$ & تعامل مر احل با گروه & \\
\hline .190 & $\cdot / \cdot \cdot 1$ & rI/Ir & $9 / \pi 1$ & $199 / 01$ & كروهها & \\
\hline$\cdot / \wedge$. & $\cdot / \cdot \cdot 1$ & $\mid r Y / \cdot r$ & $r / 11$ & rVq/II & مر احل & بازدارى \\
\hline.$/ 94$ & $\cdot / \cdot \cdot 1$ & $r Q / Y r$ & $r / 11$ & $91 / v \wedge$ & تعامل مر احل با گرووه & \\
\hline$\cdot / Y \mid$ & $\cdot / \cdot r$ & $k / F q$ & $1 D / Y F$ & $9 N / F \Delta$ & كروهها & \\
\hline$\cdot / 19$ & $\cdot / \cdot 1$ & YVY/9I & $\cdot / V r$ & 19V/A9 & مراحل & انتقال توجه \\
\hline$\cdot / V Y$ & $\cdot / \cdot 1$ & $\kappa r / \cdot 1$ & $\cdot / V Y$ & $r \mid / Y$ & تعامل مراحل با گروه & \\
\hline
\end{tabular}




\begin{tabular}{|c|c|c|c|c|c|c|}
\hline$\cdot / \cdot \Delta$ & $\cdot / 4$ & $\cdot / 94$ & $10 / T F$ & $18 / 19$ & كروهها & \\
\hline •/Ar &.$/ \cdot 1$ & $\mid \Delta F / \cdot V$ & $\cdot / N F$ & $110 / 19$ & مراحل & مهار گرى هيجانى \\
\hline . 194 &.$/ \cdot 1$ & YA/VV & $\cdot / N F$ & $r|/ \Delta|$ & تعامل مراحل با گروه & \\
\hline$\cdot / \mathrm{TV}$ & $\% \Delta$ & $9 / T V$ & V/GY & $F V / A l$ & كروهها & \\
\hline$\cdot / 91$ &.$/ .1$ & $V I / r F$ & $\cdot / q v$ & $M T / 99$ & مر احل & آغاز گرى \\
\hline$\cdot / F F$ &.$/ \cdot 1$ & $\mid r / Q F$ & $\cdot / q V$ & $9 / 19$ & تعامل مراحل با كُروه & \\
\hline.$/ 10$ & .1 .9 & $r / \cdot 1$ & $V / G F$ & rr/Gr & كرووها & \\
\hline$\cdot / \mathrm{VI}$ & $\cdot / \cdot 1$ & $\Lambda r / q V$ & .194 & $\Delta \Delta / V \Delta$ & مراحل & حافظه كارى \\
\hline$\cdot / \mathcal{A V}$ & $\cdot / \cdot 1$ & $\mid f / A$ & $\cdot 199$ & $Q / A r$ & تعامل مراحل با كَروه & \\
\hline . & $\cdot / \cdot v$ & $\Delta / A r$ & $19 / Y V$ & $\| r / r A$ & كروهها & \\
\hline •/Ar &.$/ \cdot 1$ & $10 V / F q$ & $\cdot / k \pi$ & GN/TY & مر احل & برنامهريزى \\
\hline.$/ 90$ &.$/ \cdot 1$ & ri/Ar & $\cdot / F r$ & $1 r / v q$ & تعامل مر احل با كُروه & \\
\hline • &.$/ .1$ & $\Lambda / F$ & $F / Y q$ & $M F / Y \Lambda$ & كروهها & \\
\hline$\cdot / \mathrm{vA}$ & $\cdot / \cdot \cdot 1$ & $\mid r Y / r Y$ & / & $F F / A r$ & مراحل ل & سازماندهى مواد \\
\hline.$/ 94$ &.$/ \cdot 1$ & rV/GY & . & $1 . / 1 r$ & تعامل مراحل با گروه & \\
\hline$\cdot / Y \Lambda$ & $\cdot \cdots \Delta$ & $9 / \pi r$ & $9 / \Gamma r$ & $\Delta q / \cdot \wedge$ & كروهها & \\
\hline$\cdot / V F$ & $\cdot / \cdot 1$ & १९/र४ & $\cdot / F V$ & $F Q / Y F$ & مر احل & مهار گرى \\
\hline$\cdot / 01$ &.$/ \cdot 1$ & IV/rY & $\cdot / F V$ & N/IF & تعامل مراحل با گروه & \\
\hline
\end{tabular}

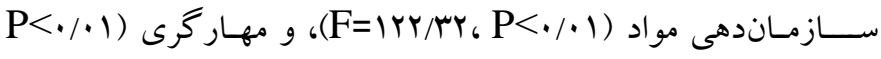

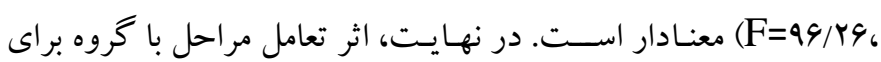

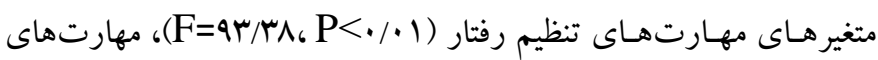

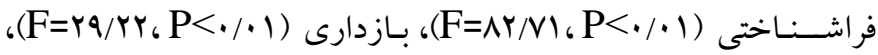

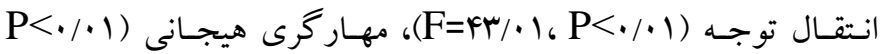

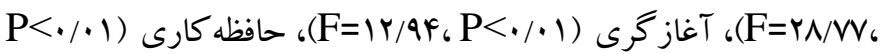

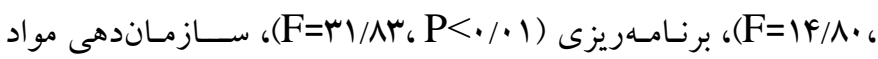

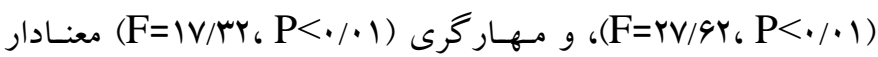
اســت. اين يـافته نشــان مى دهد كه گروههاى آزمايش و كواه از لحاظ

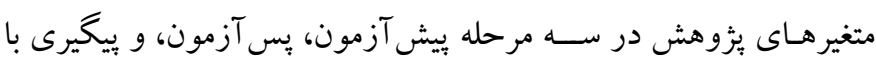
يكديكر تفاوت معنادار دارند. در ادامه جهت مقايسه دو به دوى گروهها در مؤلفههاى كنشهاى اجر ايى از آزمون مقايسه ميانخينها استفاده شده است كه نتايج آن در جدول F ارائه شده است.
جـدول ب نشـــان مى دهـــ كـه ميزان F تفـاوتهــاى بين گروهى در

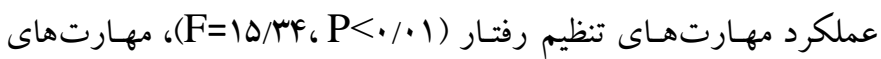
فراشــــاختى (1/1/99، P<

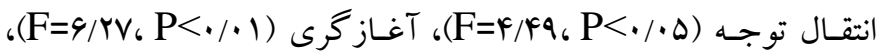

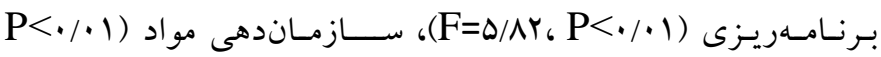
(F=N/F،

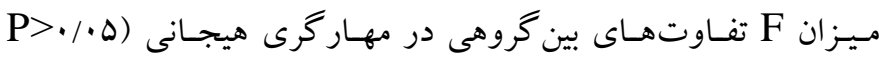

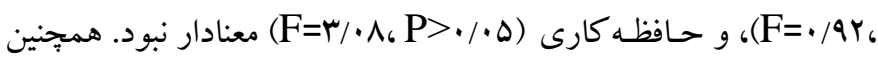
تفـاوت بين مراحسل زمـانى در ســـه مرحلـه بيش آزمون، بِ بـ آزمون، و

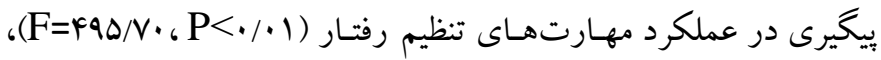

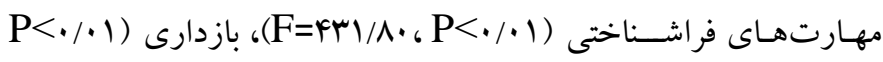
، • • •

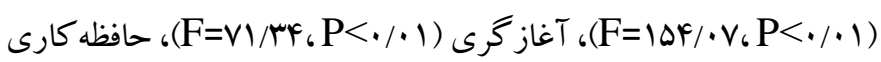

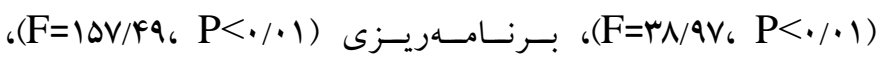


جدول ع: نتايج مقايسه ميانكين كروهها در سه مرحله ييش آزمون، يس آزمون، و ييكيرى در مؤلفههاى كنشهاى اجرايى

\begin{tabular}{|c|c|c|c|c|c|c|}
\hline سطح معنادارى & خطاى استاندارد & تفاوت ميانكين & كروه مقايسه & كروه مبنا & مرحله & مؤلفه \\
\hline$\cdot / \mu 1$ & $1 / 19$ & $-Y / V \Delta$ & نوروفيدبك & توانبخشى شناختى & & \\
\hline.$/ 9 \mathrm{~V}$ & $1 / 49$ &.$- / 49$ & كواه & توانبخى شناختى & بيش آزمون & \\
\hline.$/ 4 r$ & $1 / 19$ & $r / T r$ & كواه & نوروفيدبكك & & \\
\hline$\cdot / 144$ & $1 / 49$ & $-Y / T r$ & نوروفيدبك & توانبخشى شناختى & & \\
\hline.$\cdot \cdot 1$ & $1 / 49$ & r & كواه & توانبخى شناختى & 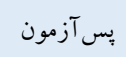 & مهارتهاى تنظيم رفتار \\
\hline.$\cdot \cdot 1$ & $1 / 99$ & $-1 . / 94$ & كواه & نوروفيدبك & & \\
\hline$\cdot / \Delta \Lambda$ & $1 / 4 r$ & $-1 / 41$ & نوروفيدبك & توانبخشى شناختى & & \\
\hline.$\cdot \cdot 1$ & $1 / 4 r$ & -11 & كواه & توانبخشى شناختى & ييخيرى & \\
\hline.. .1 & $1 / F r$ & $-9 / \Delta \wedge$ & كواه & نوروفيدبك & & \\
\hline.$/ 91$ & $r / A r$ & $1 / 19$ & نوروفيدبك & توانبخشى شناختى & & \\
\hline$\cdot / v$ & r/Ar & $-Y / Y \Delta$ & كواه & توانبخشى شناختى & ييش آزمون & \\
\hline$\cdot / 4 \Delta$ & r/Ar & $-r / 41$ & كواه & نوروفيدبك & & \\
\hline .191 & $r / Y I$ & $-Y / \cdot A$ & نوروفيدبك & توانبخشى شناختى & & \\
\hline.$/ .1$ & $r / Y)$ & $-1 \Delta / v \Delta$ & كواه & توانبخشى شناختى & ع صِ آزمون & ههارتهاى فراشناختى \\
\hline$\cdot / \cdot 1$ & $r / Y)$ & $-1 \% / 99$ & كواه & نوروفيدبكك & & \\
\hline .194 & $r / Y F$ & $-Y / 19$ & نوروفيدبك & توانبخشى شناختى & & \\
\hline.$/ .1$ & $r / M F$ & $-|r / 9|$ & كواه & توانبخشى شناختى & ييكيرى & \\
\hline.$\cdot \cdot 1$ & $r / M F$ & $-11 / v \Delta$ & كواه & نوروفيدبك & & \\
\hline$\cdot / \Delta F$ & $\cdot / \mathrm{NA}$ & $-\cdot / \wedge r$ & نوروفيدبك & توانبخشى شناختى & & \\
\hline$\cdot|r|$ & $\cdot / \mathrm{vA}$ & $-1 / 19$ & كواه & توانبخشى شناختى & ي بيش آزمون & \\
\hline.$/ 9$. & $\cdot / \mathrm{NA}$ & $-\cdot / r r$ & كواه & نوروفيدبكك & & \\
\hline$\cdot / A F$ &.$/ 9$ & $\cdot / \pi$ & نوروفيدبك & توانبخشى شناختى & & \\
\hline.$\cdot \cdot 1$ &.$/ 9$ & $-9 / \pi r$ & كواه & توانبخشى شناختى & بـ آزمون & بازدارى \\
\hline$\% \cdot .1$ & .19 & -9 & كواه & نوروفيدبك & & \\
\hline$\cdot|A|$ & $.19 \mathrm{~V}$ & $\cdot / 41$ & نوروفيدبك & توانبخشى شناختى & & \\
\hline.$/ .1$ & $.19 \mathrm{~V}$ & $-\Delta$ & كواه & توانبخشى شناختى & ييكيرى & \\
\hline.$/ .1$ & $.19 \mathrm{~V}$ & $-\Delta / F \mid$ & كواه & نوروفيدبكك & & \\
\hline$\cdot / T \Delta$ & $1 / \cdot r$ & $-1 / 99$ & نوروفيدبك & توانبخشى شناختى & & \\
\hline.$/ 99$ & $1 / \cdot r$ &.$- / 4 \Delta$ & كواه & توانبخشى شناختى & ييش آزمون & \\
\hline$\cdot / T V$ & $1 / \cdot r$ & $1 / 41$ & كواه & نوروفيدبك & & \\
\hline . &.$/ 9$. & $-1 / \Delta$ & نوروفيدبك & توانبخشى شناختى & & \\
\hline.$/ .1$ &.$/ 9$. & $-4 / 19$ & كواه & توانبخشى شناختى & يس آزمون & انتقال توجه \\
\hline.$/ .1$ &.$/ 9$. & $-r / 49$ & كواه & نوروفيدبك & & \\
\hline$\cdot / \pi r$ & $\cdot / 19$ & $-1 / \Delta$ & نوروفيدبك & توانبخشى شناختى & & \\
\hline.$/ .1$ & $\cdot / 19$ & $-r / A r$ & كواه & توانبخشى شناختى & ييخيرى & \\
\hline.$/ r$ & $\cdot / 19$ & $-Y / T r$ & كواه & نوروفيدبك & & \\
\hline.$/ 9 \mathrm{~V}$ & $1 / 14$ &.$- / r \Delta$ & نوروفيدبك & توانبخىى شناختى & & \\
\hline .190 & $1 / 1 F$ & 1 & كواه & توانبخشى شناختى & بيش آزمون & \\
\hline$\cdot / \Delta r$ & $1 / 1 F$ & $1 / r \Delta$ & كواه & نوروفيدبكك & & مهار گرى هيجانى \\
\hline . $/ A r$ & $\cdot / A F$ & $-\cdot / \Delta$ & نوروفيدبك & توانبخى شناختى & يُس آزمون & \\
\hline.$/ 1$ & $\cdot / A F$ & $-r / \Delta$. & كواه & توانبخشى شناختى & קֵ" & \\
\hline
\end{tabular}




\begin{tabular}{|c|c|c|c|c|c|c|}
\hline .1 .9 & - /AF & $-r$ & كو اه & نوروفيدبك & & \\
\hline.$/ 91$ & . & $-\cdot / r r$ & نوروفيدبك & توانبخشى شناختى & & \\
\hline$\cdot / \cdot r$ & 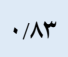 & $-r / 19$ & كواه & توانبخشى شناختى & ييخيرى & \\
\hline$\cdot / \cdot \wedge$ & 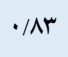 & $-1 / A r$ & كواه & نوروفيدبكك & & \\
\hline$\cdot / 9$ & $\cdot / \mathrm{VA}$ & $\cdot / \pi$ & نوروفيدبك & توانبخشى شناختى & & \\
\hline$\cdot / \Delta r$ & $\cdot /$ V4 & $-\cdot / A r$ & كواه & توانبخشى شناختى & يِيش آزمون & \\
\hline$\cdot / \mathrm{Na}$ & $\cdot / \mathrm{VA}$ & $-\cdot / \Delta$ & كواه & نوروفيدبكك & & \\
\hline$\cdot / r$ & $\cdot 191$ & $-1 / \cdot 1$ & نوروفيدبك & توانبخشى شناختى & & \\
\hline$\cdot / \cdot 1$ & .191 & $-r / \cdot \Lambda$ & كواه & توانبخشى شناختى & يس آزمون & آغاز گرى \\
\hline$\cdot / \cdot \wedge$ & $\cdot 191$ & $-r$ & كواه & نوروفيدبكك & & \\
\hline$\cdot / r F$ & $\cdot 190$ & $-1 / \cdot 1$ & نوروفيدبك & توانبخشى شناختى & & \\
\hline$\cdot / \cdot 1$ & $\cdot 190$ & $-Y / 91$ & كواه & توانبخشى شناختى & ي يخيرى & \\
\hline$\cdot / r$ & .190 & $-1 / \wedge r$ & كو اه & نوروفيدبكك & & \\
\hline - $/ A F$ & $\cdot / V \Delta$ & $\cdot \mid q 1$ & نوروفيدبك & توانبخشى شناختى & & \\
\hline$\cdot / 9 V$ & $\cdot / V \Delta$ & $\cdot 119$ & كو اه & توانبخشى شناختى & يِيش آزمون & \\
\hline$\cdot / 94$ & $\cdot / V \Delta$ & $-\cdot / r \Delta$ & كو اه & نوروفيدبكك & & \\
\hline$\cdot / 91$ & $\cdot 194$ & $-\cdot / Y \Delta$ & نوروفيدبك & توانبخشى شناختى & & \\
\hline$\cdot / \cdot r$ & . & $-Y / F 1$ & كو اه & توانبخشى شناختى & يس آزمون & حافظه كارى \\
\hline$\cdot / \cdot \Delta$ & $\cdot 194$ & $-r / 19$ & كواه & نوروفيدبك & & \\
\hline.$/ 99$ & .194 & $-\cdot / \cdot \wedge$ & نوروفيدبك & توانبخشى شناختى & & \\
\hline.$/ 1$ & $\cdot 194$ & $-1 / 91$ & كواه & توانبخشى شناختى & ييخيرى & \\
\hline$\cdot / \cdot r$ & $\cdot 194$ & l/A & كو اه & نوروفيدبكك & & \\
\hline$\cdot / v \wedge$ & 1/1r & $\cdot / V \Delta$ & نوروفيدبك & توانبخشى شناختى & & \\
\hline$\cdot / F^{F}$ & (1/1r & $-\cdot / \wedge r$ & كو اه & توانبخشى شناختى & يِيش آزمون & \\
\hline - D & 1/1r & $-1 / \Delta \Lambda$ & كواه & نوروفيدبك & & \\
\hline$\cdot / 91$ & $1 / \cdot 1$ & $-\cdot / 19$ & نوروفيدبكك & توانبخشى شناختى & & \\
\hline$\cdot / \cdot 1$ & $1 / \cdot 1$ & $-F / r \Delta$ & كواه & توانبخشى شناختى & يس آزمون & برنامهريزى \\
\hline$\% \cdot \cdot 1$ & $1 / \cdot 1$ & $-\psi / \cdot \wedge$ & كواه & نوروفيدبك & & \\
\hline$\cdot / 99$ & $1 / \cdot 1$ & $-\cdot / \cdot \wedge$ & نوروفيدبك & توانبخشى شناختى & & \\
\hline$\cdot / \cdot r$ & $1 / \cdot 1$ & $-r / A r$ & كواه & توانبخشى شناختى & ي يَيرى & \\
\hline$\cdot / \cdot r$ & $1 / \cdot 1$ & $-r / v \Delta$ & كواه & نوروفيدبك & & \\
\hline$\cdot / 9$ & $\cdot / \Delta \Lambda$ & $-\cdot / Y \Delta$ & نوروفيدبكك & توانبخشى شناختى & & \\
\hline$\cdot / 9$ & $\cdot / \Delta \Lambda$ & $-\cdot / Y \Delta$ & كواه & توانبخشى شناختى & يِيش آزمون & \\
\hline 1 & $\cdot / \Delta \Lambda$ &.$/ \cdot 1$ & كواه & نوروفيدبكك & & \\
\hline$\cdot / \mathrm{IV}$ & $\cdot / 4 \Delta$ & $-\cdot / \wedge r$ & نوروفيدبك & توانبخشى شناختى & & \\
\hline$\cdot / \cdot 1$ & $\cdot / 4 \Delta$ & $-Y / 91$ & كو اه & توانبخشى شناختى & يس آزمون & سازماندهى مواد \\
\hline$\cdot / \cdot 1$ & $\cdot / \& \Delta$ & $-Y / \cdot \wedge$ & كواه & نوروفيدبك & & \\
\hline$\cdot / r r$ & $\cdot / 49$ & $-\cdot / \wedge r$ & نوروفيدبك & توانبخشى شناختى & & \\
\hline$\cdot / \cdot 1$ & $\cdot / 4 q$ & $-r / \Delta \Lambda$ & كواه & توانبخشى شناختى & ييخيرى & \\
\hline$\cdot \cdot \cdot r$ & $\cdot / 49$ & $-1 / V \Delta$ & كواه & نوروفيدبك & & \\
\hline$\cdot / \mathrm{WV}$ & $\cdot / \wedge \Delta$ & $\cdot / \Delta \mathrm{A}$ & نوروفيدبك & توانبخشى شناختى & & \\
\hline •/Ar & $\cdot / \wedge \Delta$ & $-\cdot / \Delta$ & كواه & توانبخشى شناختى & يِيش آزمون & مهارگرى \\
\hline$\cdot / A r$ & $\cdot / \wedge \Delta$ & $-1 / \cdot 1$ & كواه & نوروفيدبكك & & \\
\hline
\end{tabular}




\begin{tabular}{|c|c|c|c|c|c|}
\hline$\cdot / 9 Y$ & .190 & $\cdot / r \Delta$ & نوروفيدبك & توانبخشى شناختى & \\
\hline$\%$ & .190 & $-r / \cdot 1$ & كواه & توانبخشى شناختى & يֶ آزمون \\
\hline$\%$ & .190 & $-r / \mu r$ & كو اه & نوروفيدبك & \\
\hline$\cdot / 99$ & $\cdot / V r$ & $-\cdot / \cdot 1$ & نوروفيدبك & توانبخشى شناختى & \\
\hline$\% r$ & $\cdot / V r$ & $-r / 94$ & كو اه & توانبخشى شناختى & ييخيرى \\
\hline r. r & $\cdot / V r$ & $-r / \Delta \Lambda$ & كو اه & نوروفيدبك & \\
\hline
\end{tabular}

بـه يـافتههـاى بـه دسـت آمـده مى توان كفـت كه نوروفيدبكك بر بهبود

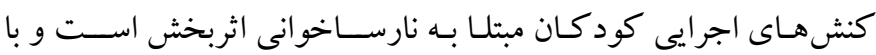

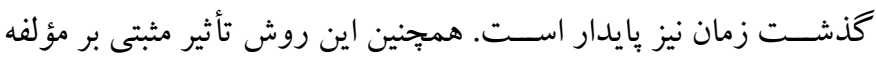
مهار گرى هيجانى نداشته است.

\section{بحث و نتيجه Fيرى}

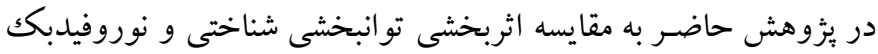

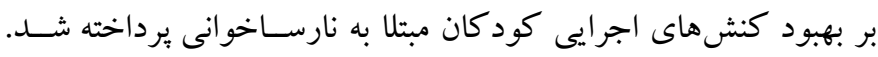

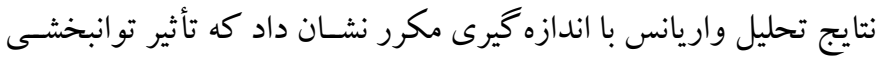

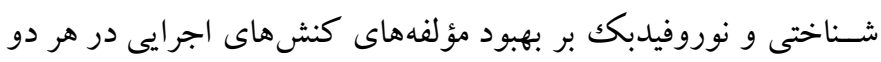

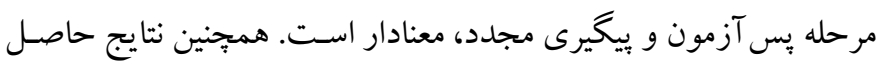

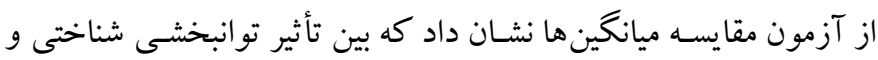
نوروفيدبك در مؤلفههاى كنش هاى اجرايى تفاوت معنادار وجود ندارد، اما بين نمرات هر دو گروه آزمايش با گو اه، تفاوت معنادار مشاهده شد.

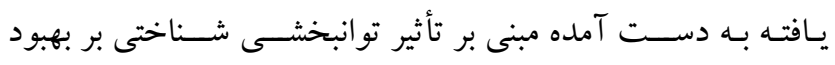

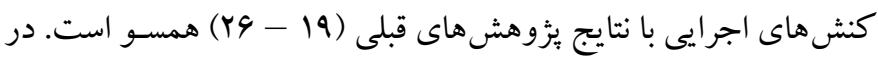

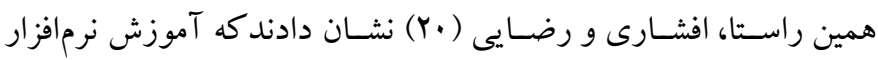
تو انبخشـى شــناختى مز اياى قابل توجهى در بيشـــر مؤلفههاى كنش هاى

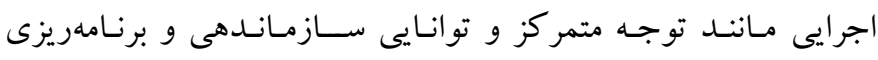

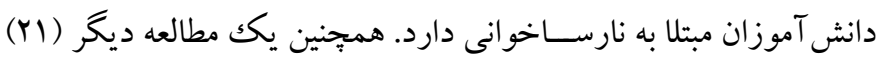
نشــان داد درمـان شـــــاختى ترميمى منجر به بهبود حافظه كارى، حافظه رويدادى، و توجه افراد مبتلا به نارساخوانى مىشود كه همسو با يافته هاى

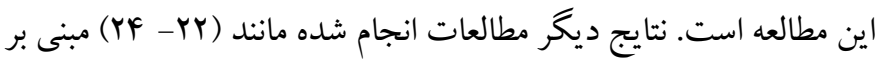

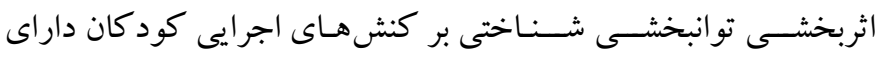

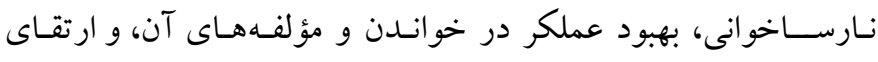
حـافظه كارى كلامى و ديدارى - فضـايى، با نتايج اين مطالعه همخوانى
با توجه به جدول F، تفاوت ميانگين گروهها به صسـورت دو به دو با

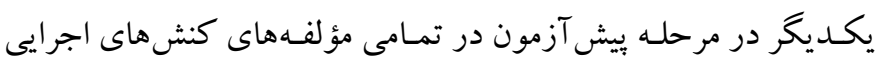

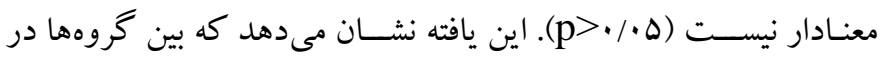

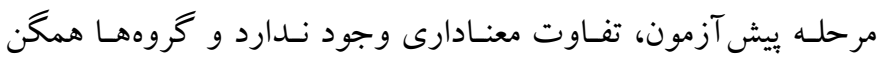

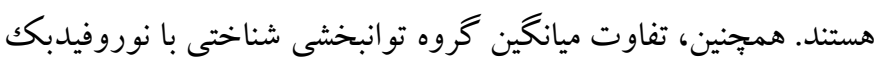

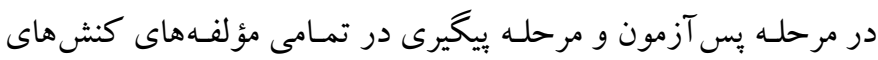

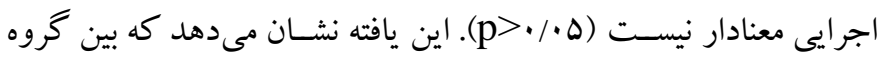

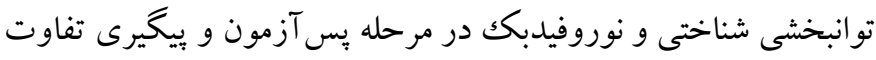

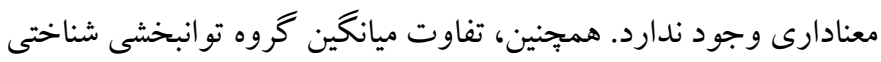

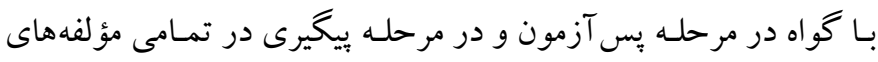

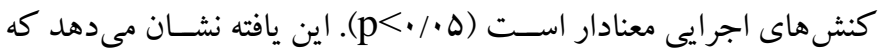

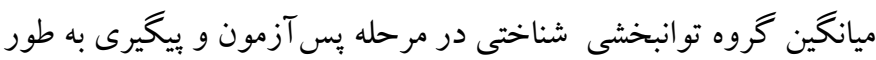

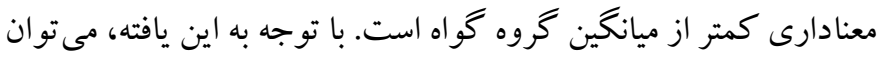
كفت كه توانبخشى شناختى بر بهبود كنش هاى اجر ايى كود كان مبتلا به

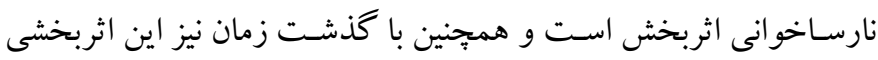
بايدار است. همجنين طبق جدول F، تفاوت ميانگين گروه نوروفيدبك با گو اه در مرحلـه پس آزمون و يّيخيرى در مؤلفـهــاى مهـارت هـاى تنظيم رفتـار،

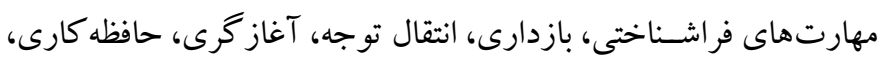

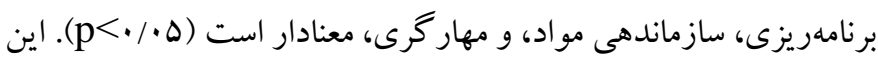

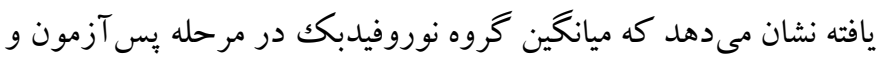

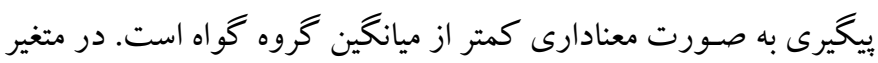

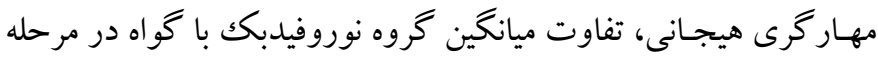

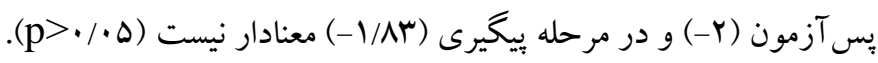

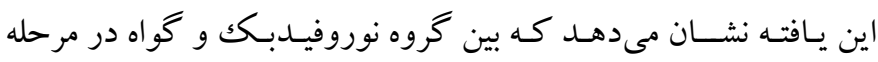

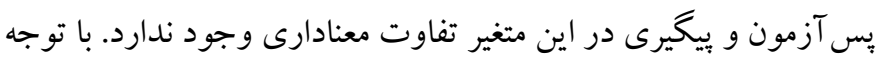


در تبيين يـافتـه به دسـت آمده مى توان كفت كه نوروفيدبك تلاش

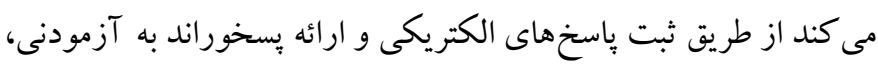

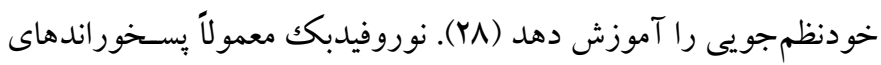
صـوتى و تصويرى ارائه مىدهد و بسخور اندهاى مثبت يا منفى به ترتيب

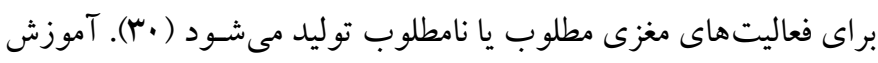

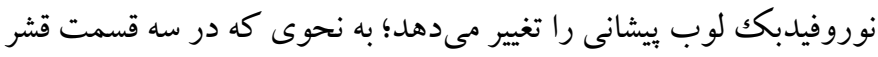

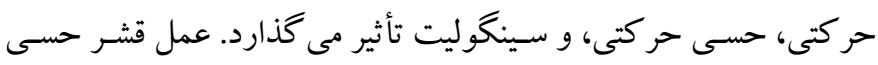

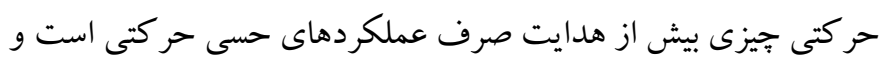

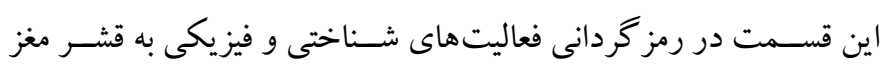

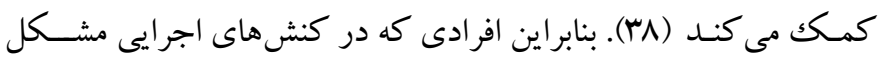

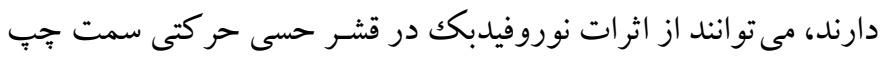
بهرهمند شـوند. نوروفيدبكك همجنين امواج بتا را افزايش و امواج تتا را

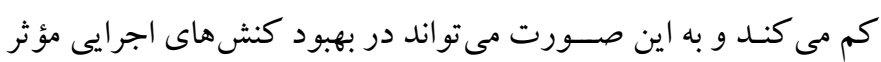

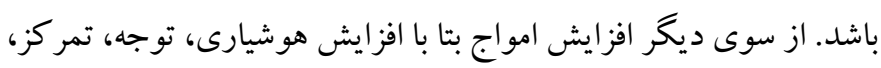

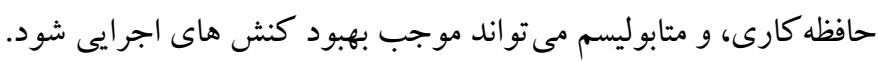

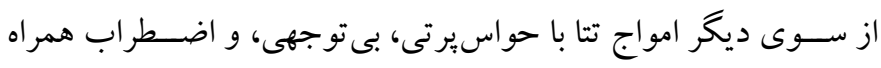

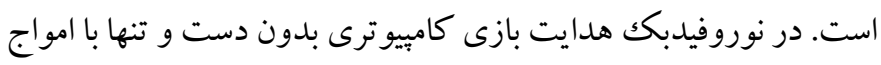

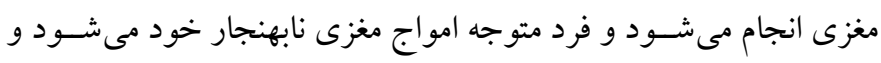

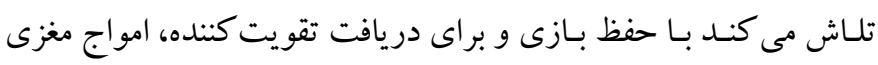

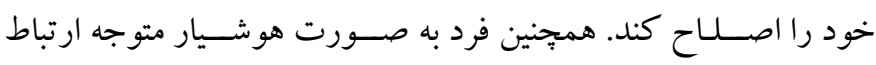

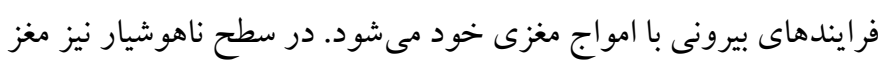

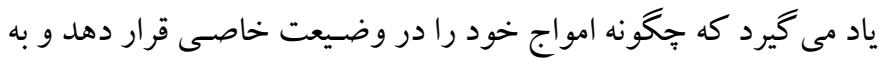

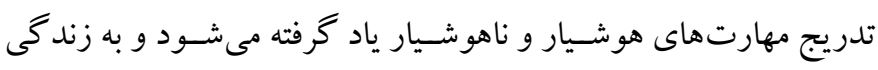

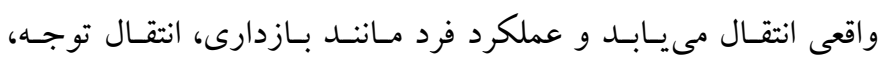

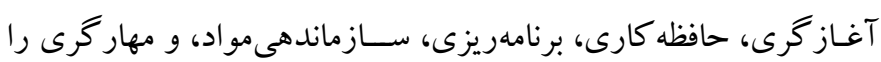

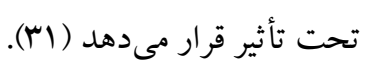

در نهايت، در تبيين عدم تفاوت بين مداخله توانبخشـى شــناختى و

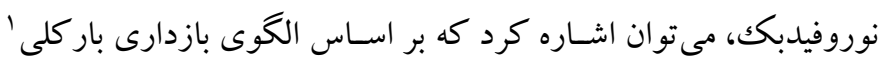
اين طور فرض مىشود كه عملكرد صحيح كنشهاى اجر ايى به عملكرد

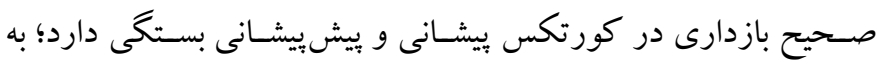

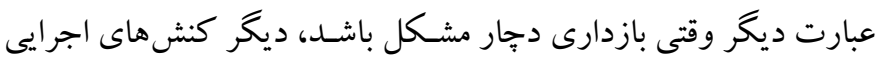

در تبيين اين يافته مى توان كفت، توانبخشـى شــناختى نوعى روش

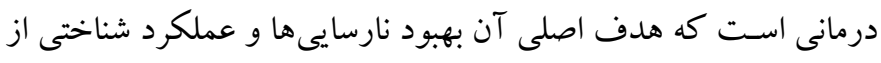

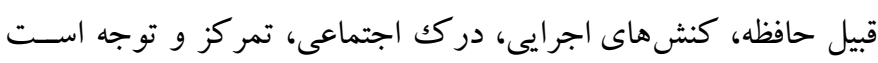

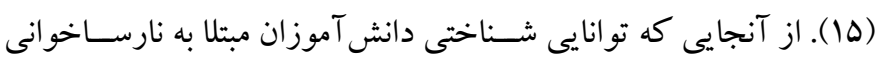
آسيب ديده است، توانبخشى شناختى مى تواند در بهبود و ارتقاء آن نقش توانش

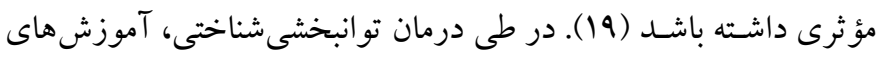

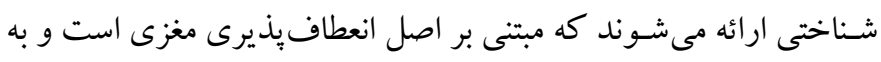

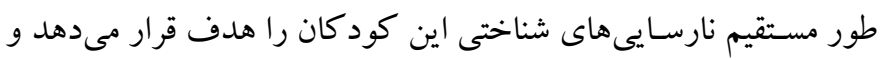

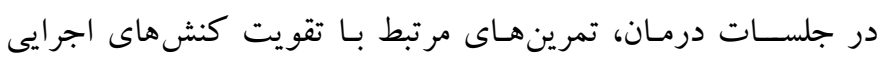

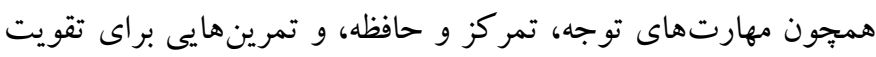
مهارتهاى كلامى و مهارت دستكارى هاى زمانى -زنجيرهسازى استفاده شد كه منجر به بهبود كنشهاى اجر ايى كود كان مبتلا به نارساخوانى شد. نتيجه اينكه توانبخشى شناختى با ارتقاى تو انايى هاى ذهنى و شناختى درد درد

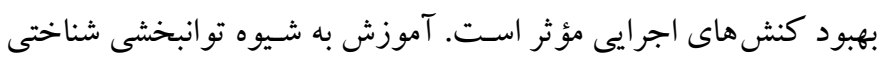

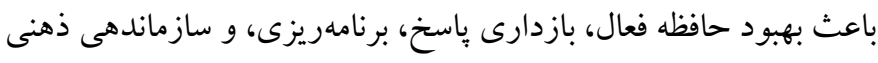

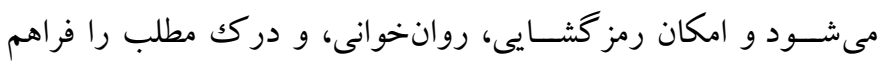

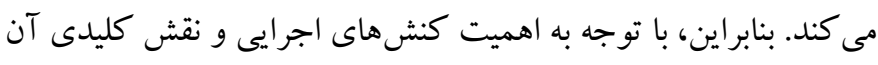

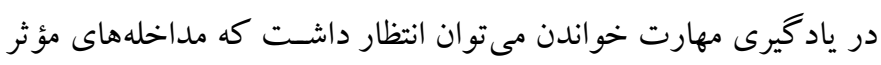
بر كنش هاى اجرايى بر ييشرفت مهارت خواندن تأثير داشته باشد.

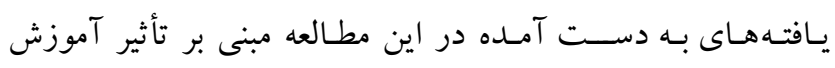

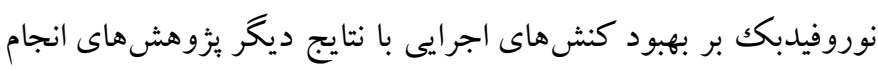

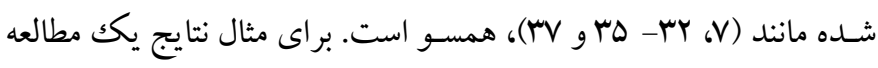
نشـF) براى القاى حالت توجه در طول فر ايندهاى شــاختى مؤثر است. همجنين

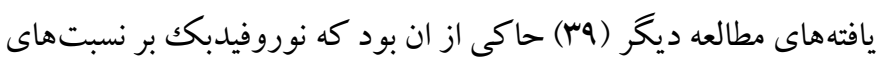

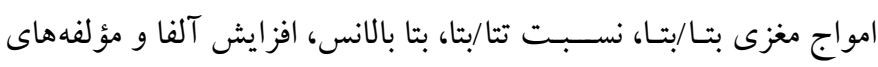

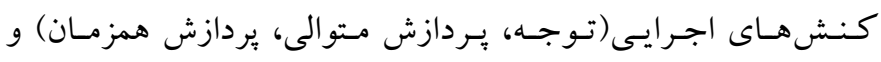

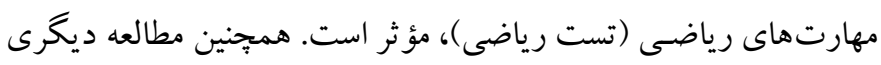

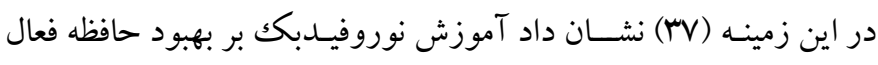

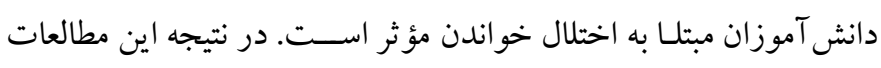

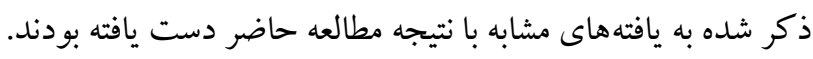




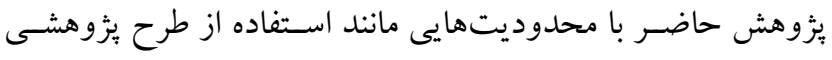



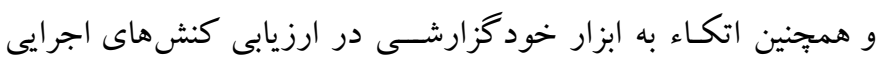

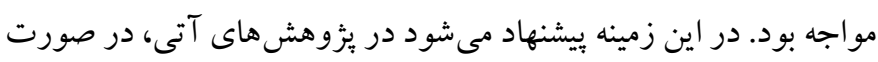
امكان از روش كاملاً آزمايشى با تعداد حجم نمونه بيشتر استئفاده شود. همجنين در سطح به كار بسته بر اساس نتايج اين مطالعه بيشنهاد مى شود

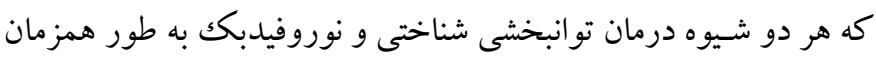
در درمان اختلالات ياد گيرى خاص مورد استفاده قرار گيرند.

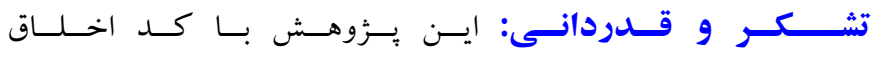
IR.IAU.RASHT.REC.1398.037 بر گرفته از رسـاله دكتراى خانم

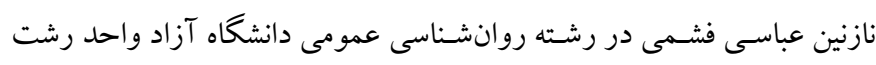

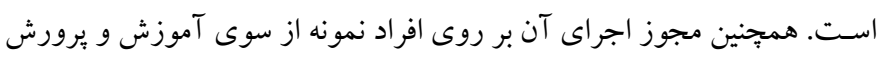

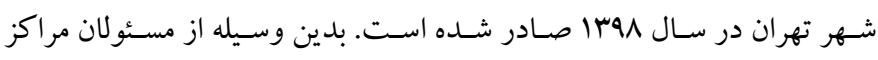

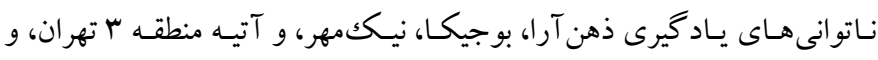

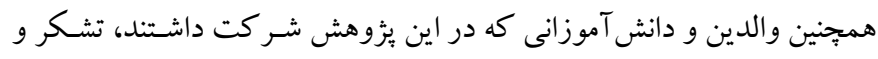
قدردانى مى شود. تضـاد منافع: در اين مقاله تضـاد منافع براى هيج كدام از نويســدكان وجود ندارد.
نيز به درستى عمل نخواهند كرد و مشكلات اين كود كان در بازدارى، با ضعف عملكرد لوب ييشانى و ييش ييشانى آنها مرتبط است (11).

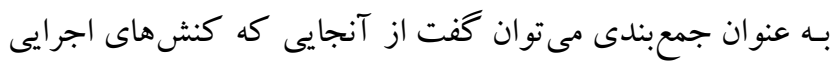

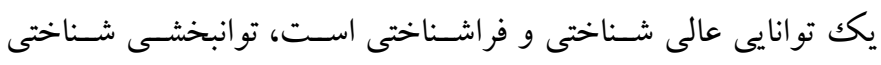

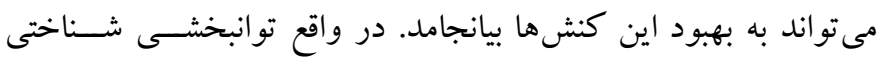

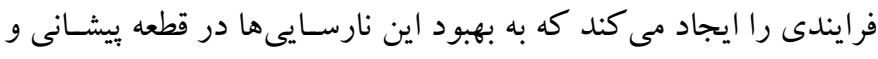

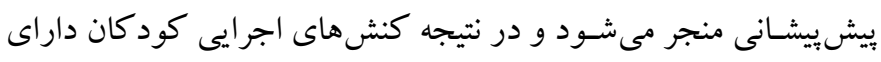

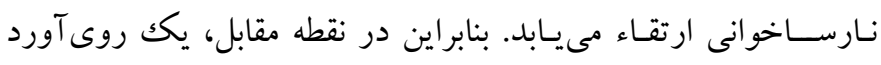

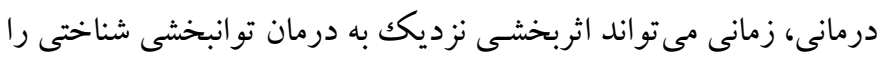

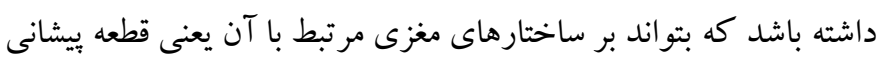

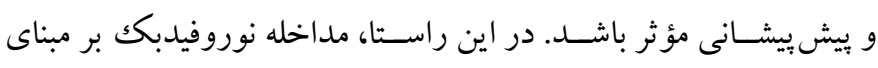

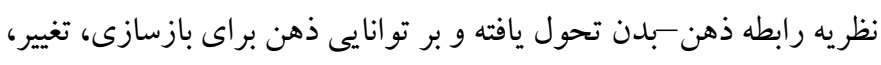

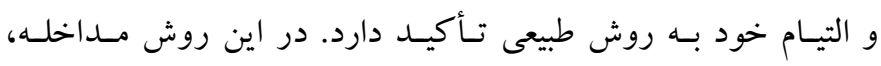

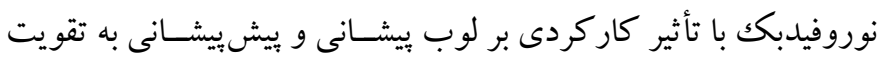

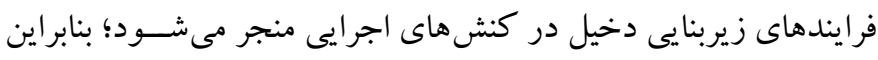

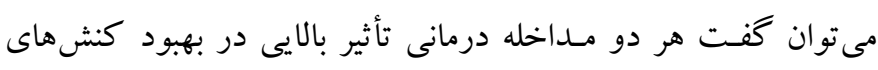
اجر ايى داشته و به اين دليل تفاوت بين دو مداخله در اين مطالعه، معنادار

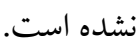

\section{References}

1. Ward A, Bush H, Braaten EB. Reading disorders/dyslexia. In: Wilson $\mathrm{HK}$, Braaten EB, 
editors. The Massachusetts general hospital guide to learning disabilities: Assessing learning needs of children and adolescents. Cham: Springer International Publishing; 2019, pp: 21-37. [Link]

2. Stoker G, Drummond K, Massengale C, Bahr C, Lin S, Vaughn S. Dyslexia and related disorders reporting study. American Institutes for Research; 2019. [Link]

3. Yousefi E, Faramarzi S, Malek Pour M, Yarmohammadian A. Comparison of the effect of executive functions training and barkley's model on reading performance and academic self-concept in students with dyslexia. Quarterly Journal of Child Mental Health. 2020; 6(4): 51-62. [Persian]. [Link]

4. Javanmard G, Asadollahifam S. Comparison of executive functions of mathematical learning disabled children with reading, writing learning disabled and normal children. Neuropsychology. 2017; 3(10): 3950. [Persian]. [Link]

5. Isquith PK, Roth RM, Gioia G. Contribution of rating scales to the assessment of executive functions. Appl Neuropsychol Child. 2013; 2(2): 125-132. [Link]

6. Bull R, Lee K. Executive functioning and mathematics achievement. Child Development Perspectives. 2014; 8(1): 36-41. [Link]

7. Moin N, Asadi Gandomani R, Amiri M. The effect of neurofeedback on improving executive functions in children with attention deficit/hyperactivity disorder. Archives of Rehabilitation. 2018; 19(3): 220-227. [Persian]. [Link]

8. Yousefi R, Soleimani M, Ghazanfariyanpoor S. Comparison between switching and creativity among bilingual and monolingual children. Archives of Rehabilitation. 2017; 18(1): 1-12. [Persian]. [Link]

9. Serpell ZN, Esposito AG. Development of executive functions: implications for educational policy and practice. Policy Insights Behav Brain Sci. 2016; 3(2): 203-210. [Link]

10. Munro BA, Weyandt LL, Marraccini ME, Oster DR. The relationship between nonmedical use of prescription stimulants, executive functioning and academic outcomes. Addict Behav. 2017; 65: 250257. [Link]

11. Mahmood Alilou M, Hashemi Nosratabad T, Fallahi A. Comparing executive functions inhibition response and sustained attention in children with learning disabilities in mathematics and normal children. Thoughts and Behavior in Clinical Psychology. 2015; 10(35): 27-36. [Persian]. [Link]

12. Hasanvandi S, Saleh Ardestani S, Ghazi Sh, Hasanvand B, Yadi F. Comparison of executive functions in students with and without specific learning disability with the characteristic reading and writing. Yafteh. 2017; 18(4): 30-39. [Persian]. [Link]

13. Mohamadi F, Karami J, Hashemi T. The effect of fernald multisensory and practice-repetition in the improvement of reading disabilities in school students. Journal of Psychological Achievements. 2011; 18(1): 169-190. [Persian]. [Link]

14. D'Mello AM, Gabrieli JDE. Cognitive neuroscience of dyslexia. Lang Speech Hear Serv Sch. 2018; 49(4): 798-809. [Link]

15. Wood RL, Fussey I. Towards a model of cognitive rehabilitation. In: Wood RL, Fussey I, editor. Cognitive rehabilitation in perspective. Routledge; 2018, pp: 3-26. [Link]

16. Baltaduoniene D, Kubilius R, Mingaila S. Computerbased cognitive rehabilitation for cognitive functions after stroke. Česká a slovenská neurologie a neurochirurgie. 2018; 81(3): 269-277. [Link]

17. Balea M, Muresanu D, Alvarez A, Homberg V, Bajenaru O, Guekht A, et al. VaD - an integrated framework for cognitive rehabilitation. CNS Neurol Disord Drug Targets. 2018; 17(1): 22-33. [Link]

18. Abbariki A, Yazdanbakhsh K, Momeni K. Investigating the effect of of computer-based cognitive rehabilitation on reducing cognitive avoidance in Students with Specific Learning disorder. Psychology of Exceptional Individuals. 2019; 9(33): 69-96. [Persian]. [Link]

19. Radfar F, Nejati V, Fathabadi J. The impact of cognitive rehabilitation on working memory and verbal fluency in dyslexic students (a single case study). Thoughts and Behavior in Clinical Psychology. 2016; 11(40): 17-26. [Persian]. [Link]

20. Afshari A, Rezaei R. The effectiveness of Sand Smart software on executive functions (focused attention, the ability to organize and plan, and auditory and visual work memory) in students with dyslexia. Journal of Learning Disabilities. 2019; 8(3): 26-48. [Persian]. [Link]

21. Anjum A. Impact of cognitive remediation therapy on working memory, episodic memory, and attention in individuals with diagnosed or possible dyslexia [Doctoral Thesis]. [Dublin, Ireland]: School of Business, BA (Honours) in Psychology, National College of Ireland; 2019, pp: 1-11. [Link]

22. Akyurek G, Efe A, Kilic BG, Bumin G. The effect of cognitive therapy on executive functions and occupational routines in children with dyslexia. Archives of Physical Medicine and Rehabilitation. 2018; 99(10): e19. [Link] 
23. Hosseinkhanzadeh A, Latif Zanjani M, Taher M. Efficacy of computer-assisted cognitive remediation (CACR) on improvement executive functions and reading performance of students with dyslexia. Neuropsychology. 2017; 2(7): 27-46. [Persian]. [Link]

24. Aghaei Sabet SS, Banijamali S, Dehshiri G. Effectiveness of cognitive rehabilitation of verbal and visuospatial working memory in improving the mathematical performance of students with dyscalculia. Journal of Exceptional Children. 2018; 18(2): 5-22. [Persian]. [Link]

25. Bayrami M, Movahedi Y, Ahmadi E. The effectiveness of cognitive rehab on the selectivedivided attention and working memory in students with dyslexia \& dyscalculia disabilities. Neuropsychology. 2017; 3(8): 9-28. [Persian]. [Link]

26. Shaw DR. A systematic review of pediatric cognitive rehabilitation in the elementary and middle school systems. NeuroRehabilitation. 2016; 39(1): 119-123. [Link]

27. Azizi A, Drikvand FM, Sepahvandi MA. Comparison of the effect of cognitive rehabilitation and neurofeedback on sustained attention among elementary school students with specific learning disorder: a preliminary randomized controlled clinical trial. Appl Psychophysiol Biofeedback. 2018; 43(4): 301-307. [Link]

28. Seilsepour M, Hamounpeyma E, Pirkhaefi A. The effect of Neurofeedback therapy sessions on female elementary students with attention deficit and Hyperactivity in Varamin city, in 2013. Navid No. 2015; 18(60): 24-33. [Persian]. [Link]

29. Brandeis D. Neurofeedback training in ADHD: More news on specificity. Clinical Neurophysiology. 2011; 5(122): 856-857. [Link]

30. Marzbani H, Marateb HR, Mansourian M. Neurofeedback: A comprehensive review on system design, methodology and clinical applications. Basic Clin Neurosci. 2016; 7(2): 143-158. [Link]

31. Cruz-Rodrigues C, Barbos T, Toledo-Piza CMJ, Miranda MC, Buen OFA. Neuropsychological characteristics of dyslexic children. Psicologia: Reflexão e Crítica. 2014; 27(3): 539-546. [Link]

32. Hojabrnia R, Tahmasebi Boroujeni S. Improvement of visual and spatial memory as a result of neurofeedback with an emphasis on decreasing beta wave and increasing SMR wave. Neuropsychology. 2018; 4(13): 21-34. [Persian]. [Link]

33. Sharifi K, Babamir H. Efficacy of neurofeedback on Brain executive functions in children with mathematics disorder. Rooyesh-e- Ravanshenasi Journal (RRJ). 2018; 7(6): 17-34. [Persian]. [Link]

34. Bruno B-V, Diego FR-R, Blanca T-C, Alvaro A-R, Gonzalo S-VJ. Neurofeedback training system with audiovisual stimuli for the attention state induction during cognitive processes [Conference Paper]. [Mexico City, Mexico]: 14th International Conference on Electrical Engineering, Computing Science and Automatic Control (CCE); 2017, pp: 1-4. [Link]

35. Eroğlu G, Aydın S, Çetin M, Balcisoy S. Improving cognitive functions of dyslexies using multi-sensory learning and EEG neurofeedback [Conference Paper]. [Izmir, Turkey]: 26th Signal Processing and Communications Applications Conference (SIU); 2018, pp: 1-4. [Link]

36. Nazari M, Taghizadeh S, Jahan A, Hashemi T, Mirnassab M. The effectiveness of neurofeedback training in reading performance and phonological awareness in dyslexic students. Journal of Modern Psychological Researches. 2014; 9(35): 189-210. [Persian]. [Link]

37. Sabaghi A, Rezaee M, Mirzakhani N, Irani A, Tabatabaee SM. Effectiveness of neurofeedback training on reading performanceand working memory in students with dyslexia. The Scientific Journal of Rehabilitation Medicine. 2017; 6(3): 11-20. [Persian]. [Link]

38. Heydarinasab L, Madani AS, Yaghoubi H, Rostami R, Kazemi R. The effectiveness of neurofeedback with computrized training in improving working memory in adults with attention deficit disorder/ hyperactivity. Yafteh. 2016; 18(1): 101-112. [Persian]. [Link]

39. Narimani M, Mohajeri Aval N, Ensafi E. Examining the effectiveness of neurofeedback treatment in brainwave, executive function and math performance of children with specific learning disorder with mathematics specifier. Journal of Learning Disabilities. 2017; 6(3): 122-142. [Persian]. [Link]

40. Vosooghifard F, Alizadeh Zarei M, Nazari MAl, Kamali M. The effect of neurofeedback training and neurofeedback with occupational therapy based on cognitive rehabilitation on executive functions in autistic children. Journal of Modern Rehabilitation. 2013; 7(2): 28-34. [Persian]. [Link]

41. Sahragard M, Alipour A, Zare H, Roshan R, Moodi M. Effectiveness of powell's cognitive rehabilitation with neurofeedback in improving executive functions, memory, and attention to veterans with post-traumatic stress disorder. Iranian Journal of War and Public Health. 2018; 10(4): 187-193. [Persian]. [Link] 
42. Heidari T, Amiri S, Molavi H. Effectiveness of Davis dyslexia correction method on reading performance of dyslexic children. Journal of Applied Psychology. 2012; 6(2): 41-58. [Persian]. [Link]

43. Rezaei A, Kermanizadeh R. The effect of reciprocal teaching on comprehension and reading improvement in fifth grades of elementary female students with dyslexia. Journal of Learning Disabilities. 2015; 4(4): 49-65. [Persian]. [Link]

44. Nodei K, Sarami G, Keramati H. The relation between function and working memory capacity and Students' reading performance: The role of age, sex and intelligence. Journal of Cognitive Psychology. 2016; 4(3): 11-20. [Persian]. [Link]
45. Klingberg T, Fernell E, Olesen PJ, Johnson M, Gustafsson P, Dahlström K, et al. Computerized training of working memory in children with ADHD-a randomized, controlled trial. J Am Acad Child Adolesc Psychiatry. 2005; 44(2): 177-186. [Link]

46. Hamzeloo M, Mashhadi A, Salehi-Fadardi J. The effectiveness of inhibition and working memory training on adhd and comorbid symptoms of prison inmates with adult attention deficithyperactivity disorder. Journal of Clinical Psychology. 2014; 6(1): 1-13. [Persian]. [Link]

47. Stevens J P. Applied multivariate statistics for the social sciences. Fifth Edition. Routledge; 2012. [Link] 